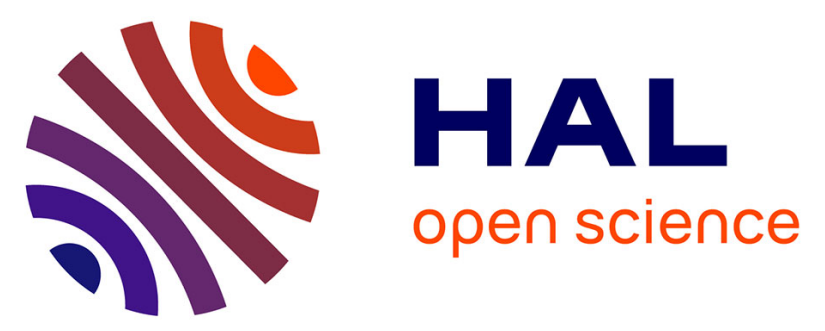

\title{
The high overtone and combination levels of SF6 revisited at Doppler-limited resolution: A global effective rovibrational model for highly excited vibrational states
}

M. Faye, V. Boudon, M. Loëte, Pascal Roy, L. Manceron

\section{To cite this version:}

M. Faye, V. Boudon, M. Loëte, Pascal Roy, L. Manceron. The high overtone and combination levels of SF6 revisited at Doppler-limited resolution: A global effective rovibrational model for highly excited vibrational states. Journal of Quantitative Spectroscopy and Radiative Transfer, 2017, 190, pp.38 47. 10.1016/j.jqsrt.2017.01.006 . hal-01510430

\section{HAL Id: hal-01510430 \\ https://hal.sorbonne-universite.fr/hal-01510430}

Submitted on 19 Apr 2017

HAL is a multi-disciplinary open access archive for the deposit and dissemination of scientific research documents, whether they are published or not. The documents may come from teaching and research institutions in France or abroad, or from public or private research centers.
L'archive ouverte pluridisciplinaire HAL, est destinée au dépôt et à la diffusion de documents scientifiques de niveau recherche, publiés ou non, émanant des établissements d'enseignement et de recherche français ou étrangers, des laboratoires publics ou privés. 


\title{
The high overtone and combination levels of $\mathrm{SF}_{6}$ revisited at Doppler-limited resolution: a global effective rovibrational model for highly excited vibrational states
}

\author{
M. Faye ${ }^{a}$, V. Boudon ${ }^{b *}$, M. Loëte ${ }^{b}$, P. Roy ${ }^{a}$, L. Manceron ${ }^{a, c *}$. \\ ${ }^{a}$ Ligne AILES-Synchrotron SOLEIL, L'Orme des Merisiers, F-91192 Gif-sur-Yvette, France, \\ ${ }^{b}$ Laboratoire Interdisciplinaire Carnot de Bourgogne, UMR 6303 CNRS-Université de Bourgogne Franche-Comté \\ 9 Av. A. Savary, BP 47870, F-21078 Dijon Cedex, France, \\ ${ }^{c}$ Laboratoire MONARIS, CNRS UMR 8233, 4 Place Jussieu, F-75252 Paris Cedex, France, \\ (Received 00 Month 200x; In final form 00 Month 200x)
}

\begin{abstract}
Sulfur hexafluoride is an important prototypal molecule for modeling highly excited vibrational energy flow and multi quanta absorption processes in hexafluoride molecules of technological importance. It is also a strong greenhouse gas of anthropogenic origin. This heavy species, however, features many hot bands at room temperature (at which only $30 \%$ of the molecules lie in the ground vibrational state), especially those originating from the lowest, $\mathrm{v}_{6}=1$ vibrational state. Using a cryogenic long path cell with variable optical path length and temperatures regulated between 120 and 163K , coupled to Synchrotron Radiation and a high resolution interferometer, Doppler-limited spectra of the $2 \nu_{1}+\nu_{3}, \nu_{1}+\nu_{2}+\nu_{3}, \nu_{1}+\nu_{3}, \nu_{2}+\nu_{3}, 3 \nu_{3}, \nu_{2}+3 \nu_{3}$ and $\nu_{1}+3 \nu_{3}$ from 2000 to $4000 \mathrm{~cm}-1$ near-infrared region has been recorded. Low temperature was used to limit the presence of hot bands. The spectrum has been analyzed thanks to the XTDS software package. Combining with previously observed weak difference bands in the far infrared region involving the $\mathrm{v}_{1}, \mathrm{v}_{2}, \mathrm{v}_{3}=1$ states, we are thus able to use the tensorial model to build a global fit of spectroscopic parameters for $\mathrm{v}_{1}=1,2, \mathrm{v}_{2}=1, \mathrm{v}_{3}=1,2,3$. The model constitutes a consistent set of molecular parameters and enable spectral rovibrational simulation for all multi-quanta transitions involving $\mathrm{v}_{1}$, $\mathrm{v}_{2}$ and $\mathrm{v}_{3}$ up to $\mathrm{v}_{1-3}=3$. Tests simulation on rovibrational transitions not yet rovibrationally assigned are presented and compared to new experimental data.
\end{abstract}

Keywords: Rotation-vibration spectroscopy of $\mathrm{SF}_{6}$, greenhouse gas, hot band, infrared absorption, tensorial formalism, Long path cell, low temperature

\section{Introduction}

Sulfur hexafluoride $\left(\mathrm{SF}_{6}\right)$, an octahedral molecule of $\mathrm{O}_{h}$ symmetry, is of fundamental interest in several aspects. In particular, it is a test case for the complex molecular spectroscopy of hexafluoride molecules of well-known technological importance $[1,2]$. This has motivated a great deal of work on multi quanta absorption using powerful IR lasers [3] on the mechanisms involved in vibrational energy relaxations [4]. Explaining the initial isotope-selective stages of multiple-photon dissociation using high power IR lasers has motivated earlier studies of the $\nu_{3}$ vibrational manifold to model the complex anharmonic effects encountered in these highly symmetric molecules. A remarkable effort was made in this direction by Pine and Robiette [5] and Patterson, Crown and Pine [6] observing the $3 \nu_{3}$ manifold between 2819 and 2832 $\mathrm{cm}^{-1}$ at high resolution using a tunable laser difference-frequency spectrometer. They could analyze a good part of the $3 \nu_{3}$ manifold absorption spectrum as an isolated band while taking into account the interaction between $l=1$ and 3 sub-bands. This analysis built up on the previously available knowledge of the $\nu_{3}$ band but could not fit in a more comprehensive analysis between all levels involving several quanta of $\mathrm{v}_{1}, \mathrm{v}_{2}$ and $\mathrm{v}_{3}$, which may be significant for laser-driven isotopically selective separation processes. Since then, further studies have led to a more global effective Hamiltonian, of larger predictive power. The infrared spectrum of gaseous $\mathrm{SF}_{6}$ has been extensively studied at low resolution [8] and therein and all its fundamentals have been observed at high to very high resolution and analyzed in detail $[9,16]$. Furthermore, $\mathrm{SF}_{6}$ is a strong greenhouse gas with a very long life time in the stratosphere $(\simeq 23900$ years $)$. Being an important Earth

* Corresponding authors

E-mail adress1: Vincent.Boudon@u-bourgogne.fr E-mail adress2: laurent.manceron@synchrotron-soleil.fr 
atmospheric pollution marker. The relevance of IR spectroscopy for the quantification of $\mathrm{SF}_{6}$ in the upper atmosphere has renewed the interest for its study [17].

The six fundamentals of $\mathrm{SF}_{6}$ can be divided in three stretching motions, $\nu_{1}$ to $\nu_{3}$, of $A_{1 g}, E_{g}$ and $F_{1 u}$ symmetry and three bending modes, $\nu_{4}$ to $\nu_{6}$, of $F_{1 u}, F_{2 g}$ and $F_{2 u}$ symmetry. As $\nu_{3}$ and $\nu_{4}$ have the same symmetry, only these two modes can present mixtures of stretching and bending coordinates at first order. Other effects such as high order Coriolis couplings can induce mixture with the IR inactive $F_{2 u}$ mode, but all these effects have been shown to be small $[16,19]$. At present, with the progress in laser technology in the near IR and UV, it will become conceivable to induce isotopically selective two-photon ionization/dissociation scheme. Thus, precise rovibrational spectroscopy for highly excited vibrational levels involving several quanta of stretching modes may become important. Past efforts in this direction have used FTIR absorption spectroscopy at moderated resolution high pressure $\times$ optical path length sample [20,21] next, photoacoustic spectroscopy with tunable lasers. Levene and Perry have used a broadly tunable OPO to investigate quaternary combinations of the stretching modes and fitted the assigned transitions with an effective model to derive anharmonic splitting constants [22]. This effort was accompanied by theoretical developments to explicit relations between quadratic and higher order potential terms and vibrational anharmonic coefficients for octahedral molecules [22, 24] and led to important predictions of anharmonic coefficients $\left(X_{i j}, G_{i j}, T_{i j}\right.$ in the notation of Hecht [25]). Later, Zhang et al. used the same technique to investigate other, weaker ternary combinations and overtone of $\mathrm{SF}_{6}$ and $\mathrm{UF}_{6}$ with a CO laser [26]. These studies were, however, limited by the laser resolution and pressure broadening effects to observation of unresolved rotational contours. Using the newly developed instrumentation at Synchrotron SOLEIL (France), involving synchrotron radiation [27, 28], a cryogenic long path cell [29] and high sensitivity detectors [30], rotationally resolved spectra could be acquired for such very weak transitions (band intensities of ca 0.02 to $0.0005 \mathrm{~km} / \mathrm{mole}$ ) and are presented here. In this study we increase the level of our previous effective global model [31] to take into account the $3 \nu_{3}$ band in full, as well as new data on $\nu_{3}, \nu_{1}+\nu_{3}, \nu_{2}+\nu_{3}, \nu_{1}+\nu_{2}+\nu_{3}$ and $3 \nu_{3}$ transitions. This is combined with previously acquired data on $\nu_{3}-\nu_{2}, \nu_{3}-\nu_{1}$ [31], $2 \nu_{3}$ [32,33], $2 \nu_{3}-\nu_{3}$ bands and Raman active fundamentals $\nu_{1}$ and $\nu_{2}$ Ref. $[13,15]$. Our present goal is thus now to provide a model and a consistent effective parameter set enabling to recalculate with its rotational structure, any vibrational band with stretching mode quantum numbers $\mathrm{v}_{1}, \mathrm{v}_{2}=1,2$ and $\mathrm{v}_{3}=1,2,3$.

\section{Theoretical model}

The theoretical model used here is based on the cubic tensor formalism and the vibrational extrapolation developed by the Dijon group [10]. We simply recall the principles here. Considering an $\mathrm{XY}_{6}$ molecule as $\mathrm{SF}_{6}$, the vibrational levels are grouped in series of polyads called $P_{k}$ with $k=0, \ldots, n$. For $k=0$, we have $P_{0}$ which is the ground state $(G S)$. The Hamiltonian operator is thus written as follow:

$$
\mathcal{H}=\mathcal{H}_{\left\{P_{0} \equiv G S\right\}}+\mathcal{H}_{\left\{P_{1}\right\}}+\ldots+\mathcal{H}_{\left\{P_{k}\right\}}+\ldots+\mathcal{H}_{\left\{P_{n-1}\right\}}+\mathcal{H}_{\left\{P_{n}\right\}}
$$

where the different $\mathcal{H}_{\left\{P_{k}\right\}}$ terms which contain the rovibrational operators are expressed in the following form:

$$
\mathcal{H}_{\left\{P_{k}\right\}}=\sum_{\text {all indexes }} t_{\{s\}\left\{s^{\prime}\right\}}^{\Omega(K, n \Gamma) \Gamma_{v} \Gamma_{v}^{\prime}} \beta\left[\varepsilon V_{\{s\}\left\{s^{\prime}\right\}}^{\Omega_{v}\left(\Gamma_{\nu} \Gamma_{v}^{\prime}\right) \Gamma} \otimes R^{\Omega(K, n \Gamma)}\right]^{\left(A_{1 g}\right)} .
$$

In this equation (2), the $t^{\Omega(K, n \Gamma) \Gamma v \Gamma^{\prime} v}$ are the parameters to be determined, while ${ }^{\varepsilon} V_{\{s\}\left\{s^{\prime}\right\}}^{\Omega_{v}\left(\Gamma_{v} \Gamma_{v}^{\prime}\right) \Gamma}$ and $\mathrm{R}^{\Omega(K, n \Gamma)}$ are vibrational and rotational operators, respectively, and of respective degree $\Omega \mathrm{v}$ and $\Omega$. $\beta$ is a factor that allows the scalar terms $\left(\Gamma=A_{1 g}\right)$ to match the usual terms like $B_{0} J^{2}$, etc. To generalize, we have: 


$$
\beta=\left\{\begin{array}{cl}
\sqrt{3}(\sqrt{3} / 4)^{\Omega / 2} & \text { if }(K, n \Gamma)=\left(0,0 A_{1 g}\right) . \\
1 & \text { Otherwise }
\end{array}\right.
$$

The order of each individual term is defined as $\Omega+\Omega_{v}-2$.

In this model we deal with an effective Hamiltonian which is obtained, for a given polyad $P_{k}$, by the projection of $H$ in the $P_{n}$ Hilbert subspace; see equation (3).

$$
\begin{aligned}
H^{<P_{n}>} & =P^{<P_{n}>} \mathcal{H} P^{<P_{n}>} \\
& =H_{\{\mathrm{GS}\}}^{<P_{n}>}+H_{\left\{P_{1}\right\}}^{<P_{n}>}+\ldots+H_{\left\{P_{k}\right\}}^{<P_{n}>}+\ldots+H_{\left\{P_{n-1}\right\}}^{<P_{n}>}+H_{\left\{P_{n}\right\}}^{<P_{n}>} .
\end{aligned}
$$

This Hamiltonian expression allow the systematic treatment of any polyad system.

The calculation of the effective Hamiltonian matrix was performed in the coupled rovibrational basis

$$
\left|\left[\Psi_{v}^{\left(C_{v}\right)} \otimes \Psi_{r}^{\left(J, n C_{r}\right)}\right](C)\right\rangle
$$

where $\Psi_{r}^{\left(J, n C_{r}\right)}$ is a rotational wavefunction with angular momentum $J$, rotational symmetry species $C_{r}$ and multiplicity index $n$ and $C$ the overall symmetry species $\left(C=C_{v} \otimes C_{r}\right)$. The effective dipole moment operator, used to calculate transition intensities is expanded in a similar way. It is expanded here up to order 2 (see below) and its matrix elements are calculated in the Hamiltonian's eigenbasis set.

\section{Experimental}

Because of the weakness of the difference bands or multi quanta transitions combined with the presence of hot bands at room temperature, a long optical path length at low temperature was required. In the farand mid-IR, several high resolution spectra were recorded on the AILES Beamline on the synchrotron light source SOLEIL coupled to the Bruker $125 \mathrm{HR}$ interferometer [27, 28] using the newly developed cryogenic long path cell regulated at temperature between 125 and $153 \mathrm{~K}$ along the entire optical path. This setup has been fully described elsewhere [29]. In the near IR (>2000 cm-1) a quartz halogen lamp was used as a source. A spectrum with a gas pressure of 4.5 mbar of $\mathrm{SF}_{6}$ (Air Liquide, France, $99.99 \%$ purity) was recorded at $0.002 \mathrm{~cm}^{-1}$ resolution in the $600-80 \mathrm{~cm}-1$ region, using boxcar apodization, $5.06 \mathrm{~cm} / \mathrm{s} \mathrm{scanner}$ velocity, a $6 \mu \mathrm{m} \mathrm{Si} /$ Mylar beamsplitter and a $4 \mathrm{~K}$-cooled Si composite bolometer with a $1.5 \mathrm{~ms}$ rise time and a cold, $600 \mathrm{~cm}^{-1}$ low-pass filter. 576 interferograms were averaged in a total recording time of about 38 hours and processed against a background of the empty cell taken at the same $163 \mathrm{~K}$ temperature at $0.01 \mathrm{~cm}^{-1}$ resolution. Spectra in the mid IR range were acquired at $0.002 \mathrm{~cm}^{-1}$ resolution using a $\mathrm{KBr} / \mathrm{Ge}$ beamsplitter and a home-made high sensitivity $\mathrm{HgCdTe}$ detector [30] using path lengths varied between 15 and $93 \mathrm{~m}$. Spectra in the near infrared region were taken between 2000 and $4000 \mathrm{~cm}^{-1}$ with an InSb detector, using 93 and $27 \mathrm{~m}$ optical path length with 5 and 1.5 mbar sample pressure, respectively. For these measurements, the diamond cell outer windows used for the MIR/ FIR were replaced by from diamond to AR-coated ZnSe, improving the optical throughput by a factor of 1.9. Spectra were zero-filled, corrected for channelling effects and calibrated using well-known water, carbon dioxide or carbonyl sulphide rotational lines [34].

\section{Global strategy for the simultaneous fit of $\mathrm{SF}_{6}$ data}

In this work, we gather data from both infrared and Raman measurements to achieve a global fit of the ensemble of $\nu_{1}, \nu_{2}, \nu_{3}, \nu_{1}+\nu_{3}, \nu_{2}+\nu_{3}, 2 \nu_{3}, 2 \nu_{3}-\nu_{3}, \nu_{1}+\nu_{2}+\nu_{3}, 3 \nu_{3}, \nu_{3}-\nu_{1}$ and $\nu_{3}-\nu_{2}$ bands of $\mathrm{SF}_{6}$.

The $\nu_{1}$ and $\nu_{2}$ data obtained from Raman measurements in Refs. [13, 15] and 2 $\nu_{3}, 2 \nu_{3}-\nu_{3}$ obtained by double resonance technique are derived from Ref. [35]. The $\nu_{3}-\nu_{1}$ and $\nu_{3}-\nu_{2}$ data were also given in Ref. [31]. For $\nu_{3}, \nu_{1}+\nu_{3}, \nu_{2}+\nu_{3}, \nu_{1}+\nu_{2}+\nu_{3}, 3 \nu_{3}$ bands, we found that it was possible to improve 
notably the measurements precision using the SOLEIL synchrotron setup. So, high resolution analyses of the bands are shown in the sections below. In order to access the anharmonicity implying the $\mathrm{v}_{1}=\mathrm{v}_{2}=1$ state, we also measured the $\nu_{1}+\nu_{2}+\nu_{3}$ ternary combination band. The global fit of all these data provides a consistent set of parameters allowing to predict a large number of other transitions implying the $\nu_{1}$, $\nu_{2}$ and $\nu_{3}$ fundamental modes of $\mathrm{SF}_{6}$. As a test of efficiency of the predictive power of this model, we present in the last section, predictions of $\nu_{1}+3 \nu_{3}$ and $\nu_{2}+3 \nu_{3}$ bands and new measurements of the ternary transitions at the Doppler-limited resolution.

\section{The $\nu_{3}$ band}

The $\nu_{3}$ band of $\mathrm{SF}_{6}$ has been the object of many studies (see Refs. [8, 9] and therein). These investigations were performed using $\mathrm{CO}_{2}$ laser absorption spectroscopy method with a very high precision, but these concerned transitions with low $J$ values. In the course of the present study, while revisiting the $\nu_{3}$ data, even at our resolution, we noticed that the available parameters did not allow a completely satisfactory simulation of the entire $\nu_{3}$ band, especially for high $J$ value transitions. A new spectrum in the $\nu_{3}$ region was recorded using the SOLEIL synchrotron source and the cryogenic multi pass cell with $69 \mathrm{~m}$ of optical path. $\mathrm{SF}_{6}$ was diluted with $\mathrm{N}_{2}$ in order to obtain very low partial pressures of $\mathrm{SF}_{6}$ and record spectra near $125 \mathrm{~K}$ with virtually no hot bands. Table 1 summarizes the different conditions of recording the spectrum. By using the parameters of Ref. [11] to calculate the spectrum, we found a good agreement between the simulation and the experiment for low $J$ values $(J \leq 33)$. For higher $J$ in both $P$ and $R$ branches $(J \geq 33)$ however, the line positions were getting further to the experiment and the standard deviation was found to be up to $0.005 \mathrm{~cm}^{-1}$. It was thus required to achieve a new fit to improve the Hamiltonian parameters. Fig. 1 shows the simulated (in red) and experimental (in blue) spectrum of the $\nu_{3}$ band. The fit residuals are shown by black markers at the bottom of the figure. The standard deviation now appears to be of the order of $0.003 \mathrm{~cm}^{-1}$.

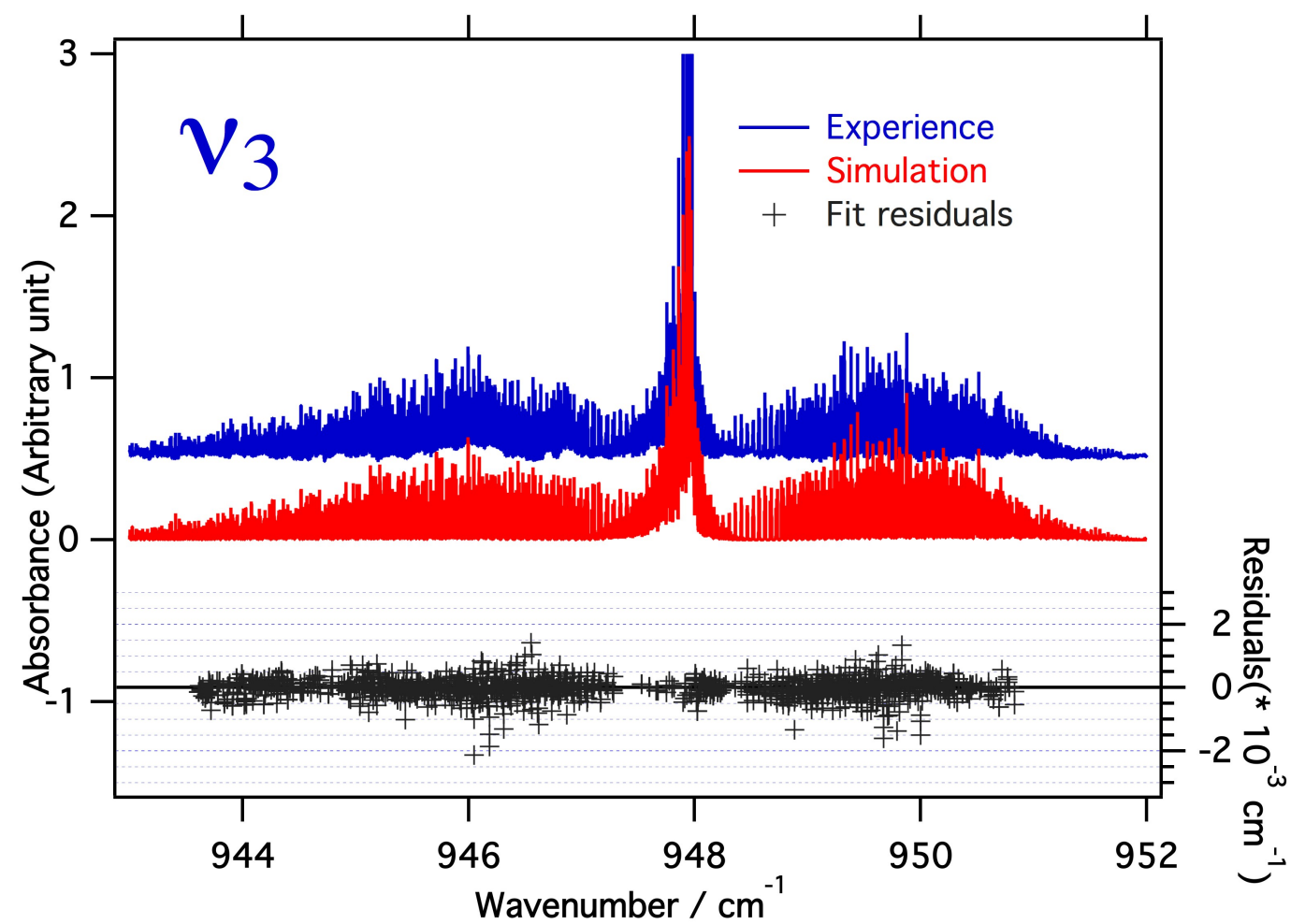

Figure 1. Comparison between the simulation(red) and the experiment (blue) spectrum recorded over the whole $\nu_{3}$ band, showing the agreement achieved. It should be noticed that the strong $\mathrm{Q}$ branch is saturated in the experimental spectrum. 
Table 1. Summary of the four different conditions of measurement of $\nu_{3}$.

\begin{tabular}{lccccc}
\hline Conditions & $\mathrm{P}\left(\mathrm{N}_{2}+\mathrm{SF}_{6}\right)(\mathrm{mbar})$ & $\mathrm{P}\left(\mathrm{SF}_{6}\right)(\mathrm{mbar})$ & $\mathrm{OPL}(\mathrm{cm})$ & $\mathrm{T}(\mathrm{K})$ & Resolution $\left(\mathrm{cm}^{-1}\right)$ \\
\hline Condition 1 & 1.15 & $1.24 \times 10^{-5}$ & 6900 & 138 & 0.002 \\
Condition 2 & 1.16 & $2.42 \times 10^{-5}$ & 6900 & 125 & 0.002 \\
Condition 3 & 1.16 & $3.53 \times 10^{-5}$ & 6900 & 125 & 0.002 \\
Condition 4 & 1.16 & $3.53 \times 10^{-5}$ & 6900 & 173 & 0.002 \\
\hline OPL: Optical Path Length & & & & \\
$\mathrm{P}\left(\mathrm{SF}_{6}\right):$ Partial pressure of $\mathrm{SF}_{6}$ & & & \\
$\mathrm{P}\left(\mathrm{N}_{2}+\mathrm{SF}_{6}\right):$ Total Pressure of $\mathrm{N}_{2}+\mathrm{SF}_{6}$ & & & \\
$\mathrm{~T}:$ Temperature &
\end{tabular}

\section{The $\nu_{1}+\nu_{3}$ and $\nu_{2}+\nu_{3}$ bands}

The $\nu_{1}+\nu_{3}$ and $\nu_{2}+\nu_{3} \mathrm{SF}_{6}$ bands had previously been recorded at very low temperature, $25 \mathrm{~K}$, thanks to a molecular supersonic jet technique; the Jet-AILES setup [31]. At that low temperature the structure of spectrum was very simplified but the resolution was limited to $0.005 \mathrm{~cm}^{-1}$. In this study 444 rovibrational lines were assigned and fitted for $\nu_{2}+\nu_{3}$ and 123 for $\nu_{1}+\nu_{3}$. The main goal of this study was to refine the anharmonicity constants $X_{31}$ and $X_{32}$ in order to calculate their corresponding hot bands $\nu_{1}+\nu_{3}-\nu_{1}$ and $\nu_{2}+\nu_{3}-\nu_{2}$.

In a first attempt at a global fit, it was found, however, that the deviation between observed and calculated lines was greater in this series. To improve the analysis for these two bands, we performed new infrared absorption measurements in this region, using the cryogenic multi-pass cell. For these measurements, we used a $\mathrm{SF}_{6}$ sample cooled down to $153 \mathrm{~K}$, at $0.14 \mathrm{mb}$ of pressure and we set the optical path to $15 \mathrm{~m}$. Under these conditions, we could double the resolution to $0.0025 \mathrm{~cm}^{-1}$ and increase largely the number of observed transitions.

By using the HTDS program, based on a tensorial formalism of the Hamiltonian, we performed new analyses of both $\nu_{1}+\nu_{3}$ and $\nu_{2}+\nu_{3}$ bands. For each band, the Hamiltonian is developed up to the sixth order. The maximum value of the rotational quantum number $J_{\max }$ is equal to 63 and 72 for $\nu_{1}+\nu_{3}$ and $\nu_{2}+\nu_{3}$ respectively. For the two bands, we have now increased significantly the number of assignments. For $\nu_{1}+\nu_{3}$ we assigned and fit 1163 line positions, versus 123 in the previous study, with a standard deviation down to $0.279 \times 10^{-3} \mathrm{~cm}^{-1}$. The $X_{13}$ anharmonicity constant is determined to be $-2.90888(8)$ $\mathrm{cm}^{-1}$ with improved accuracy with respect to the previous determinations $\left(-2.902(3) \mathrm{cm}^{-1}\right.$ in Ref. [21], $-2.9088(2) \mathrm{cm}^{-1}$ in Ref. [31]) and the prediction $-2.94 \mathrm{~cm}^{-1}$ [24]. For $\nu_{2}+\nu_{3}$ we assigned and fitted 3256 line positions versus 444 in the previous study, with a standard deviation of $0.450 \times 10^{-3} \mathrm{~cm}^{-1}$. Because of the two sub-levels $F_{1 u}$ and $F_{2 u}$ of this band, the anharmonicity constants should be given by the expressions $X_{23}+G_{22}+8 T_{23}$ for $F_{1 u}$ and $X_{23}+G_{22}-8 T_{23}$ for $F_{2 u}$. But due to the lack of knowledge for $2 \nu_{2}$, we have no value for $G_{22}$. We could nevertheless derive the $T_{23}$ constant from the energies of the sub-levels $\left(F_{1 u} \longrightarrow 1587.717292 \mathrm{~cm}^{-1}, F_{2 u} \longrightarrow 1591.192261 \mathrm{~cm}^{-1}\right)$ and thus $T_{23}=-0.2172 \mathrm{~cm}^{-1}$, which compares favorably with the prediction of -0.213 [24]. Fig. 2 and Fig. 3 show the result of the analysis of $\nu_{1}+\nu_{3}$ and $\nu_{2}+\nu_{3}$ respectively illustrating the agreement between the experiment in blue color and the simulation in red color. At the bottom of each figures, we also show the fit residuals of the line assignments. 


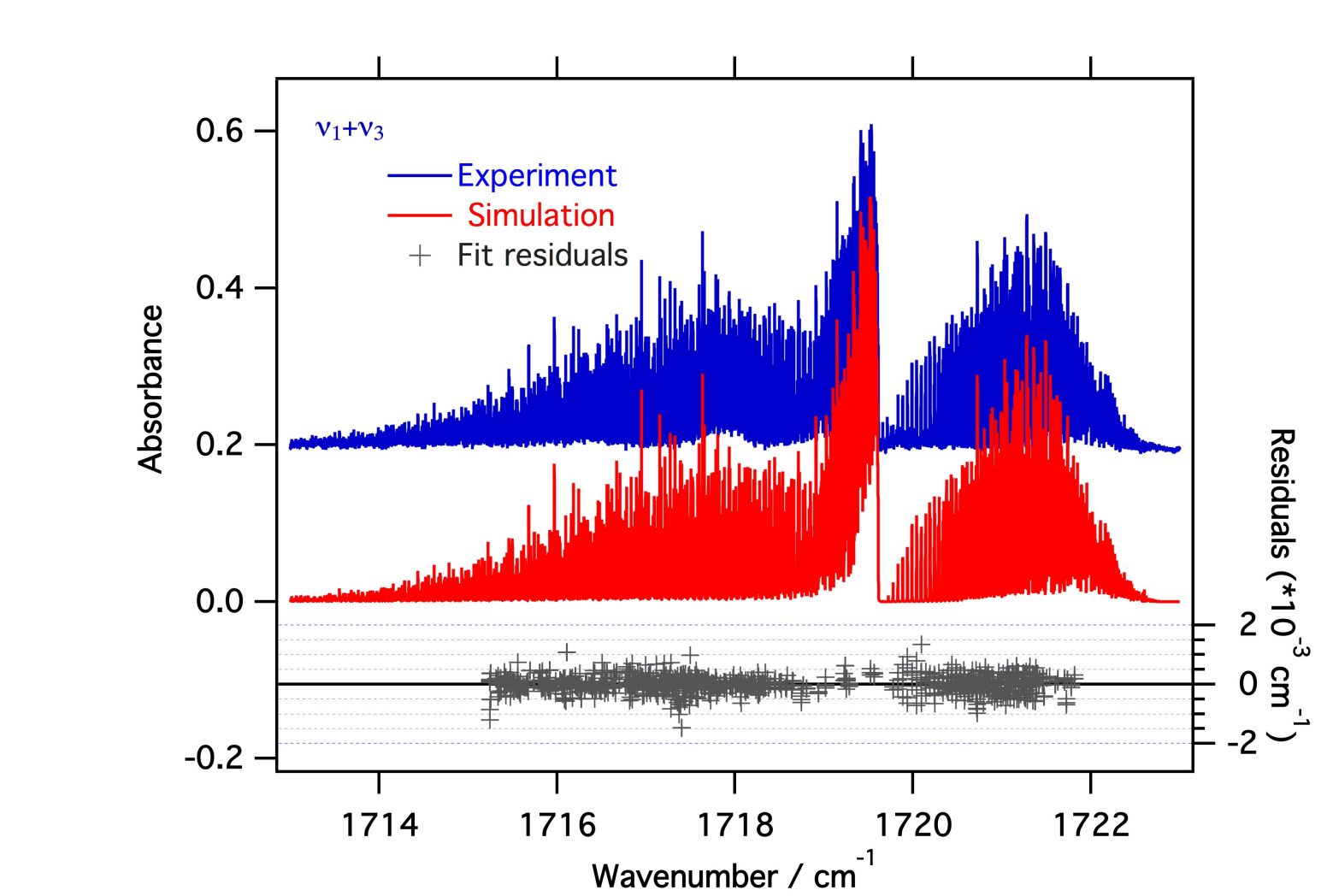

Figure 2. Comparison between the simulation (red) and the experiment (blue) spectra recorded over the whole $\nu_{1}+\nu_{3}$ band.

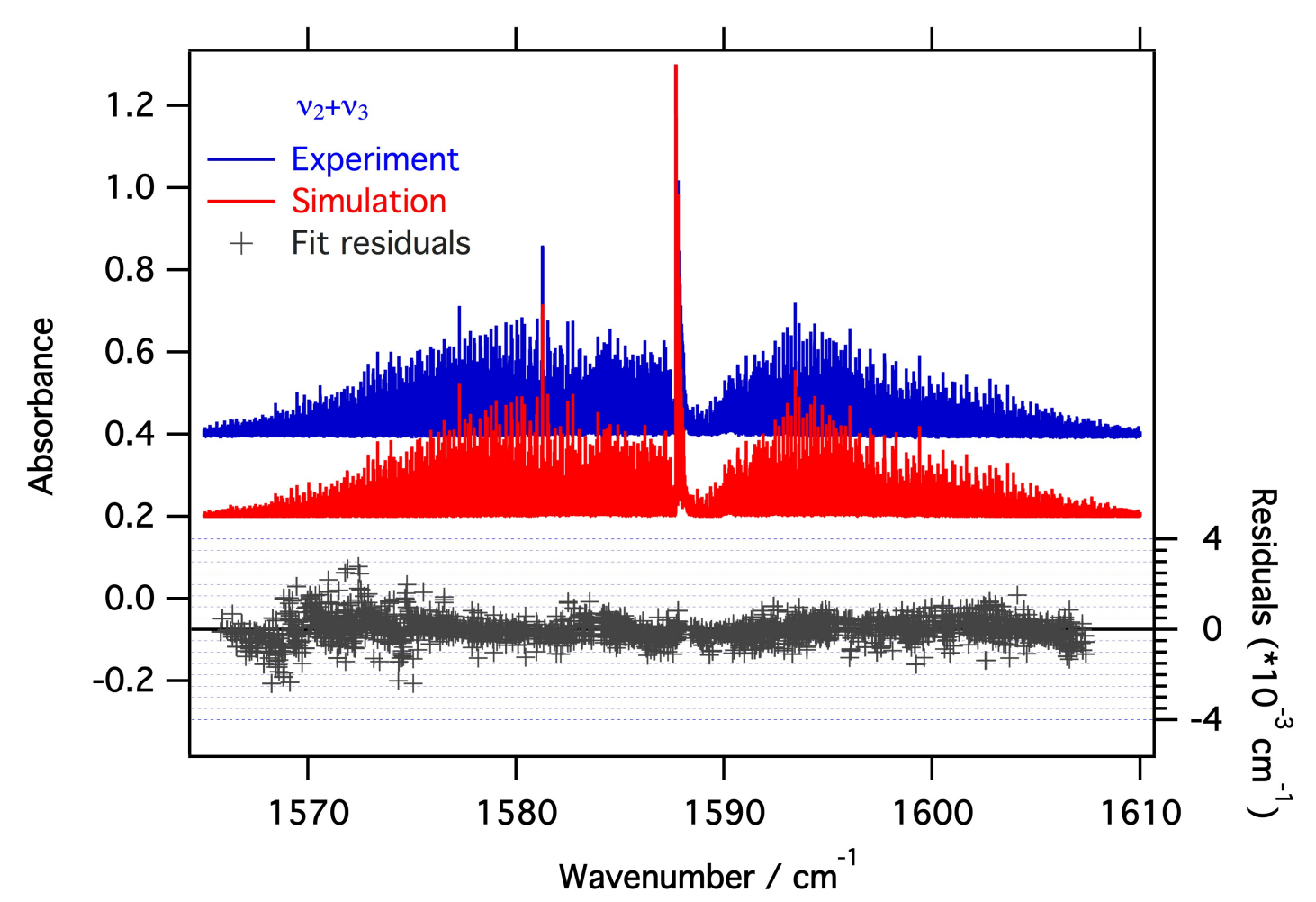

Figure 3. Comparison between the simulation (red) and the experiment (blue) spectra recorded over the whole $\nu_{1}+\nu_{3}$ band. 
7 The $\nu_{1}+\nu_{2}+\nu_{3}$ band

By considering the symmetry species $A_{1 g}, E_{g}$ and $F_{1 u}$ of the $\nu_{1}, \nu_{2}$ and $\nu_{3}$ modes respectively, the direct product gives $A_{1 g} \otimes E_{g} \otimes F_{1 u} \longrightarrow E_{g} \otimes F_{1 u} \longrightarrow F_{1 u} \oplus F_{2 u}$. Thus, the $\nu_{1}+\nu_{2}+\nu_{3}$ band has two sub-levels $F_{1 u}$ and $F_{2 u}$. In the infrared absorption spectrum only the $F_{1 u}$ component arises and gives a relatively simple structure to analyze. The simulation was performed by developing the Hamiltonian to the $6^{\text {th }}$ order. We assigned line positions up to $J_{\max }=90$ and fitted 2856 transitions with 21 parameters. Fig. 4 shows the experiment vs simulation spectra for this band and the fit residuals the bottom of the figure. The standard deviation is here equal to $0.860 \times 10^{-3} \mathrm{~cm}^{-1}$. The analysis of $\nu_{1}+\nu_{2}+\nu_{3}$ band allows to a simultaneous access of $\nu_{1}, \nu_{2}$ and $\nu_{3}$ parameters and also to the anharmonicity constant $X_{12}$ of the $\nu_{1}+\nu_{2}$ band which is not active in infrared because of its $E_{g}$ symmetry. This anharmonicity constant is found to be $X_{12}=-2.4816(3) \mathrm{cm}^{-1}$, which compares very well to the $-2.49 \mathrm{~cm}^{-1}$ prediction of Ref. [24], and not as favorably the $-2.37(1) \mathrm{cm}^{-1}$ previous estimate [20].

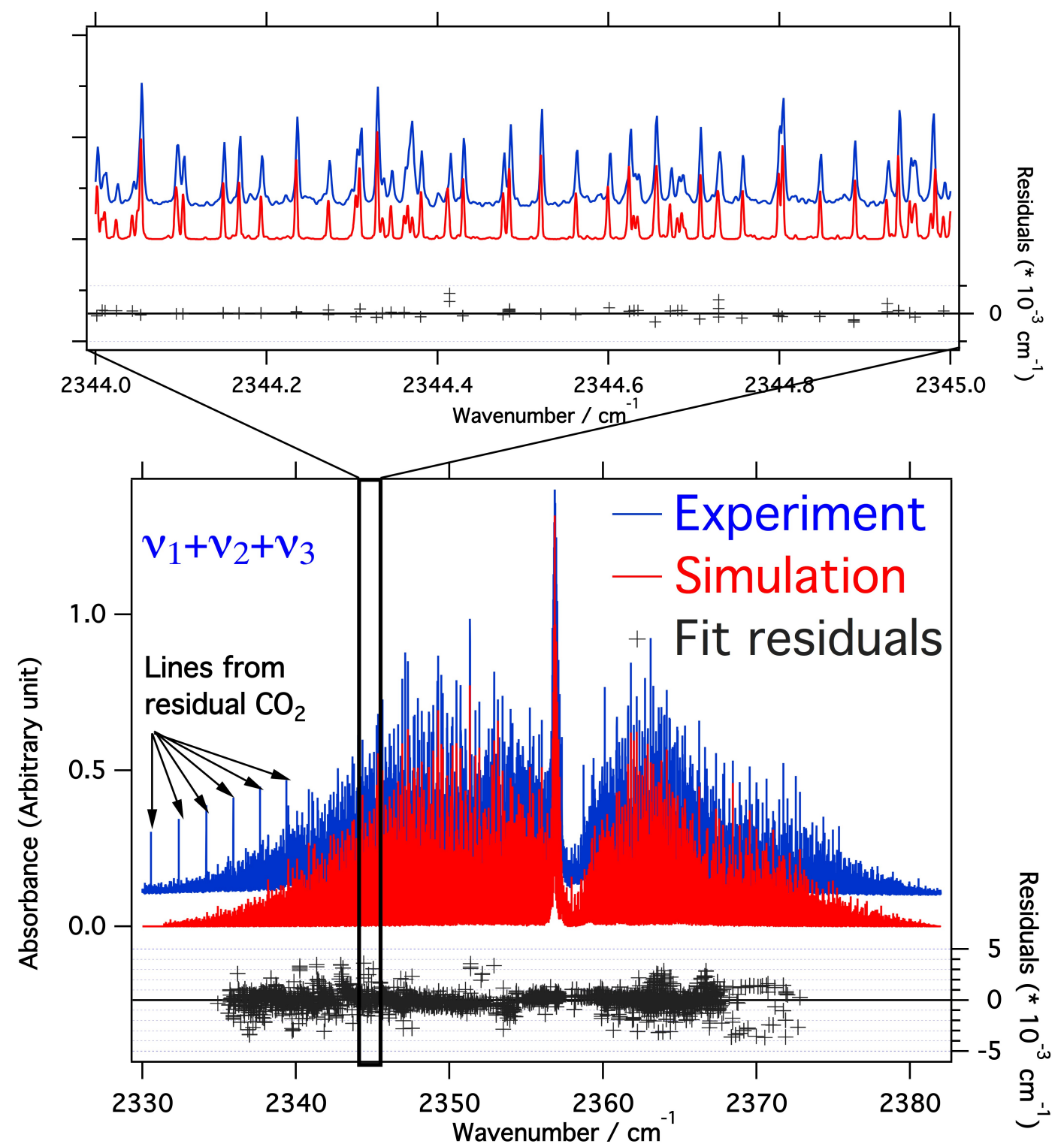

Figure 4. The $\nu_{1}+\nu_{2}+\nu_{3}$ band, Experiment in blue vs simulation in red with a zoom in the $P$ branch, showing the good agreement of the fit. 


\section{Study on the $3 \nu_{3}$ band}

The $2 \nu_{3}$ band is of $g$ symmetry (with $A_{1 g}, E_{g}, F_{2 g}$ sublevels), and is therefore forbidden for infrared direct one-photon absorption. A study of this band using Doppler Free Two-Photon spectroscopy is reported in [7]. The $3 \nu_{3}$ band is of $u$ symmetry (with $A_{2 u}, F_{2 u}, 2 F_{1 u}$ sublevels), and is infrared active. It is therefore the most direct way to access the $X_{33}, G_{33}$ and $T_{33}$ anharmonic constants that determine the $n \nu_{3}$ ladder, see Equation (5). This band has thus been the object of several previous analyses by A. S. Pine et al [5, 6]. In both studies they used the same experimental setup: a tunable laser difference-frequency spectrometer coupled to a White cell. In the first study, the authors performed the analysis by focusing only on one $\mathrm{F}_{1 u}$ sub-level (with essentially $l=1$ character). While their second investigation presents an analysis using a perturbed Hamiltonian model which takes into account the $l=1$ character and the interaction between the sub-levels [6]. This last study brought a more complete understanding of the structure of the $3 \nu_{3}$ band. In these previous studies, however, the maximum number of lines assigned and fitted was only around 700 with $J_{\max } \leq 33$.

In this paper, we present a new analysis of the band using a spectrum recorded at the SOLEIL Synchrotron with a resolution of $0.0025 \mathrm{~cm}^{-1}$, thanks to the multi pass cell coupled to a high resolution Fourier Transform spectrometer. We could extend the assignment up to 3759 lines with $J_{\max }=77$ far more complete than the previous assignement [6] with an improved standard deviation of $1.157 \times 10^{-3} \mathrm{~cm}^{-1}$. The line assignment and the fitting process in this work were performed by using XTDS as described above. From this analysis, we could find the anharmonic constants $X_{33}, G_{33}$ and $T_{33}$ and make a comparison with the values in the literature. These values are shown in Table 2 . In this table, we also show the correspondence of symmetry species between the $T_{d}$ and $O_{h}$ groups. This correspondence allows us to express the vibrational anharmonic terms of $2 \nu_{3}$ and $3 \nu_{3}$ in the $O_{h}$ group according to Hecht's expressions [25] that were developed for tetrahedral molecules. A general agreement is obtained, even though the differences are beyond the standard deviations indicated.

Equation (5) gives the general expression for vibrational terms of the vibrational energy which contains the anharmonic constants.

$$
E_{i}^{v i b}=\omega_{i}\left(v_{i}+\frac{d_{i}}{2}\right)+X_{i i}\left(v_{i}+\frac{d_{i}}{2}\right)^{2}+W\left(i, \text { symmetry }, G_{i i}, T_{i i}\right)
$$

In this equation, $\omega_{i}$ gives the harmonic frequency, $v_{i}$ the vibrational quantum number and the $d_{i}$ represents the degeneracy of the normal mode. The $W$ term gives the splitting contribution according to the symmetry of the sub-level. As for $X_{i i}, G_{i i}$ and $T_{i i}$ are anharmonic parameters of the vibrational level.

Table 2. In this table is shown: The correspondence of symmetry species between $T_{d}$ and $O_{h}$ groups, the values of $X_{33}, G_{33}$ and $T_{33}$ anharmonic constants. Vibrational expression terms and their values according to the symmetry of the sub-level are also shown.

\begin{tabular}{|c|c|c|c|c|c|}
\hline \multicolumn{6}{|c|}{ Correspondence of symmetry species between $T_{d}$ and $O_{h}$ groups } \\
\hline$T_{d}$ & $A_{1}$ & $A_{2}$ & $E$ & $F_{1}$ & $F_{2}$ \\
\hline$O_{h}$ & $A_{1 g}+A_{2 u}$ & $A_{2 g}+A_{1 u}$ & $E_{g}+E_{u}$ & $F_{1 g}+F_{2 u}$ & $F_{2 g}+F_{1 u}$ \\
\hline \multicolumn{6}{|c|}{ Comparison of derived anharmonicity constants. } \\
\hline References & $\nu_{3}\left(\mathrm{~cm}^{-1}\right)$ & & $X_{33}\left(\mathrm{~cm}^{-1}\right)$ & $G_{33}\left(\mathrm{~cm}^{-1}\right)$ & $T_{33}\left(\mathrm{~cm}^{-1}\right)$ \\
\hline [7] & & & $-1.7456(5)$ & $0.924986(13)$ & $-0.248651(2)$ \\
\hline [6] & 948.007500 & & $-1.742565^{a}$ & $0.918805(13)$ & $-0.246351(3)$ \\
\hline$[24]$ & & & $-1.680^{a}$ & $0.861^{a}$ & $-0.215^{a}$ \\
\hline This work & $948.102512(21)$ & & $-1.7378(6)$ & $0.9122(8)$ & $-0.2498(1)$ \\
\hline Symmetry species & $\left(2 \nu_{3}\right)$ & Vibrational anharmonic terms & & Values $\left(\mathrm{cm}^{-1}\right)$ & \\
\hline$A_{1 g}$ & $\left(2 \nu_{3}\right)_{A 1 g}$ & $=2 \times \nu_{3}+2 X_{33}-2 G_{33}$ & & $1889.01[7]$ & \\
\hline$E_{g}$ & $\left(2 \nu_{3}\right)_{E g}$ & $=2 \times \nu_{3}+2 X_{33}+6 G_{33}+12 T_{33}$ & & $1891.58[7]$ & \\
\hline$F_{2 g}$ & $\left(2 \nu_{3}\right)_{F 2 g}$ & $=2 \times \nu_{3}+2 X_{33}+4 G_{33}-8 T_{33}$ & & $1896.68[7]$ & \\
\hline Symmetry species & $\left(3 \nu_{3}\right)$ & Vibrational anharmonic terms & & Values $\left(\mathrm{cm}^{-1}\right)$ & \\
\hline$A_{2 u}$ & $\left(2 \nu_{3}\right) A 2 u$ & $=3 \times \nu_{3}+6 X_{33}+6 G_{33}-24 T_{33}$ & & 2845.3488 & This work \\
\hline$F_{2 u}$ & $\left(2 \nu_{3}\right)_{F 2 u}$ & $=3 \times \nu_{3}+6 X_{33}+6 G_{33}-4 T_{33}$ & & 2840.3531 & This work \\
\hline$F_{1 u} l=3$ & $\left(2 \nu_{3}\right)_{F 1 u}$ & $=3 \times \nu_{3}+6 X_{33}+G_{33}+6 T_{33}+\left[\left(5 G_{33}+6 T_{33}\right)+384 T_{33}^{2}\right]^{1 / 2}$ & & 8239.0432 & This work \\
\hline$F_{1 u} l=1$ & $\left(2 \nu_{3}\right)_{F 1 u}$ & $=3 \times \nu_{3}+6 X_{33}+G_{33}+6 T_{33}-\left[\left(5 G_{33}+6 T_{33}\right)+384 T_{33}^{2}\right]^{1 / 2}$ & & 2827.5455 & This work \\
\hline
\end{tabular}




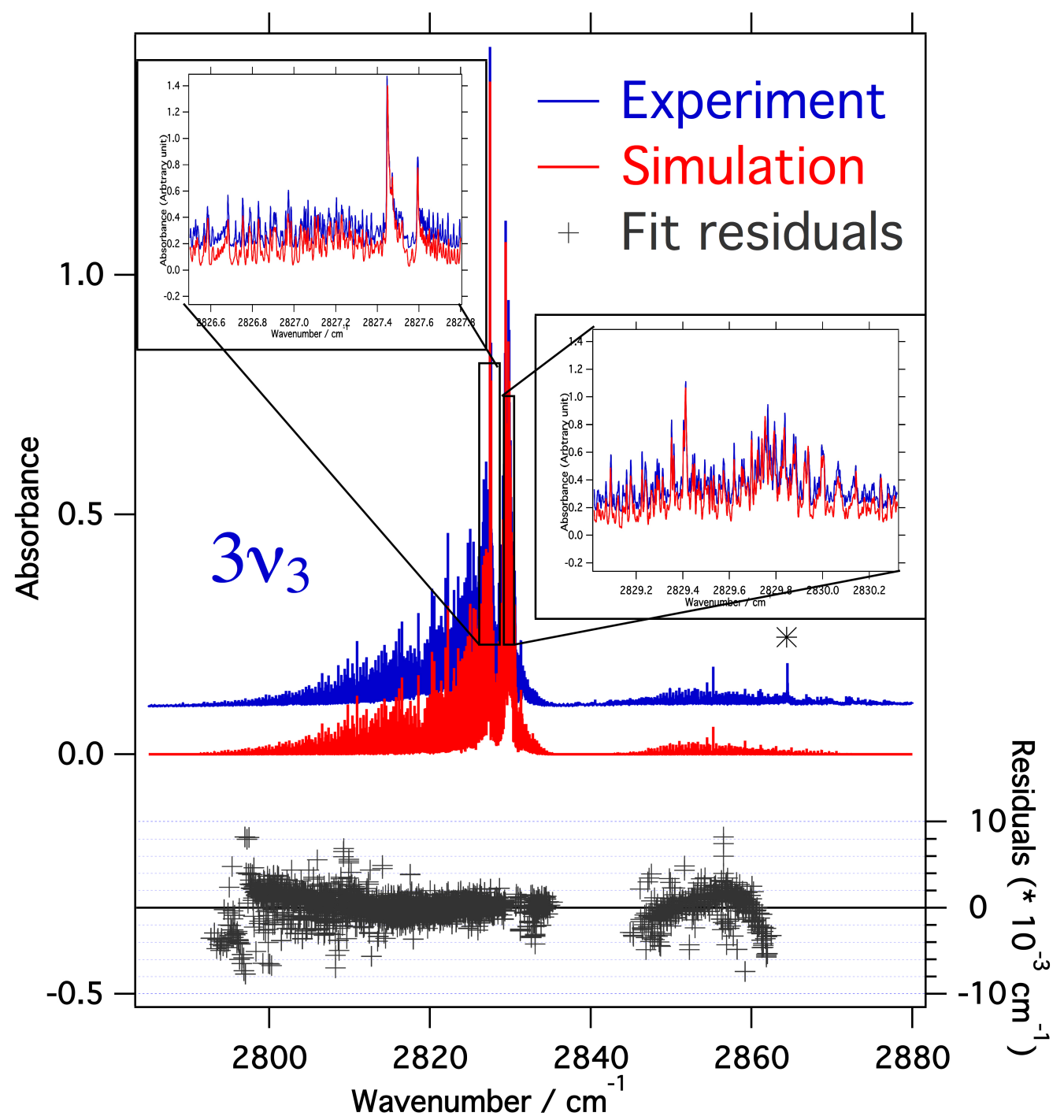

Figure 5. Comparison between the simulation(red) and the experiment (blue) spectrum recorded over the whole $3 \nu_{3}$ band, showing the agreement achieved. The asterisk at $2864 \mathrm{~cm}^{-1}$ designates another weak transition which corresponds to $3 \nu_{2}+\nu_{3}$ according to [22].

9 Simultaneous fit of $\nu_{1}, \nu_{2}, \nu_{3}, \nu_{1}+\nu_{3}, \nu_{2}+\nu_{3}, 2 \nu_{3}, \nu_{1}+\nu_{2}+\nu_{3}, 3 \nu_{3}, \nu_{3}-\nu_{1}, \nu_{3}-\nu_{2}$ data

$\mathrm{SF}_{6}$ bands are usually studied as isolated bands by assuming that they do not interact with each other, but some interactions may exist between several bands and in turn have influences on the effective Hamiltonian parameters. To take into account such interactions and thus bring more coherence to the band analyses, we have achieved a global fit of 21102 lines of eleven bands implying the $\nu_{1}, \nu_{2}$ and $\nu_{3}$ stretching modes. To make this global fit, we built a unique parameter file of all the $\nu_{1}, \nu_{2}, \nu_{3}, \nu_{1}+\nu_{3}, \nu_{2}+\nu_{3}, 2 \nu_{3}, \nu_{1}+\nu_{2}+\nu_{3}$, $3 \nu_{3}, \nu_{3}-\nu_{1}, \nu_{3}-\nu_{2}$ bands thanks to the HTDS software. In this analysis process, each level is represented by a polyad $\mathrm{P}_{i}$ (Table 3 ) and the bands by transitions between polyads (Table 4). Table 4 summarizes also the number of line positions fitted, the $J_{\max }$ values and the standard deviation corresponding to each band. The total number of fitted lines and the global standard deviation are also shown at the bottom of the table. To initiate the analysis, we took $\nu_{1}, \nu_{2}, 2 \nu_{3}, \nu_{3}-\nu_{1}$ and $\nu_{3}-\nu_{2}$ data from [31], while the $\nu_{3}$, $\nu_{1}+\nu_{3}, \nu_{2}+\nu_{3}, \nu_{1}+\nu_{2}+\nu_{3}$ and $3 \nu_{3}$ initial data are those obtained from the analysis in sections $5,6,7$ and 8 presented above. 
Table 3. Polyad representation of the energy levels

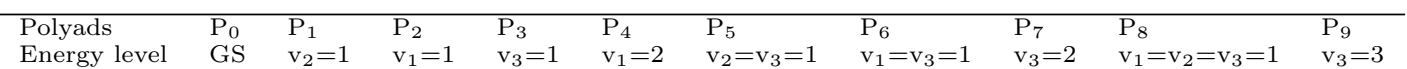

Table 4. Summary of the global fit statistics:

\begin{tabular}{llllll}
\hline Transitions & & Bands & Assigned Frequency Data & $J_{\max }$ value & Standard Deviation (mk) \\
\hline $\mathrm{P}_{1} \leftarrow \mathrm{P}_{0}$ & $\longrightarrow$ & $\nu_{2}$ & 543 & 58 & 2.713 \\
$\mathrm{P}_{2} \leftarrow \mathrm{P}_{0}$ & $\longrightarrow$ & $\nu_{1}$ & 85 & 107 & 0.531 \\
$\mathrm{P}_{3} \leftarrow \mathrm{P}_{0}$ & $\longrightarrow$ & $\nu_{3}$ & 1643 & 67 & 0.308 \\
$\mathrm{P}_{5} \leftarrow \mathrm{P}_{0}$ & $\longrightarrow$ & $\nu_{2}+\nu_{3}$ & 3256 & 72 & 0.450 \\
$\mathrm{P}_{6} \leftarrow \mathrm{P}_{0}$ & $\longrightarrow$ & $\nu_{1}+\nu_{3}$ & 1163 & 63 & 0.279 \\
$\mathrm{P}_{7} \leftarrow \mathrm{P}_{0}$ & $\longrightarrow$ & $2 \nu_{3}$ & 128 & 59 & 0.057 \\
$\mathrm{P}_{8} \leftarrow \mathrm{P}_{0}$ & $\longrightarrow$ & $\nu_{1}+\nu_{2}+\nu_{3}$ & 2856 & 73 & 0.879 \\
$\mathrm{P}_{9} \leftarrow \mathrm{P}_{0}$ & $\longrightarrow$ & $3 \nu_{3}$ & 3759 & 77 & 1.157 \\
$\mathrm{P}_{3} \leftarrow \mathrm{P}_{1}$ & $\longrightarrow$ & $\nu_{3}-\nu_{2}$ & 6450 & 79 & 0.305 \\
$\mathrm{P}_{3} \leftarrow \mathrm{P}_{2}$ & $\longrightarrow$ & $\nu_{3}-\nu_{1}$ & 987 & 59 & 0.365 \\
$\mathrm{P}_{7} \leftarrow \mathrm{P}_{3}$ & $\longrightarrow$ & $2 \nu_{3}-\nu_{3}$ & 232 & 5903 \\
\hline \multicolumn{7}{l}{ Total number of fitted line positions: $21102 ;$ Global Standard deviation: 0.795} \\
\hline
\end{tabular}

\section{Prediction of $\nu_{1}+3 \nu_{3}$ and $\nu_{2}+3 \nu_{3}$ bands}

After performing a global fit of data including the $\nu_{1}, \nu_{2}, \nu_{3} 2 \nu_{3}$ and $3 \nu_{3}$, it becomes possible to predict multi quanta combinations between $v_{1}=1, v_{2}=1, v_{2}=1, v_{3}=1, v_{3}=2$ and $v_{3}=3$ levels. The only remaining concern is the small anharmonic shift coming from the neglect of higher order anharmonic terms.

To test the efficiency of our global model of the Hamiltonian parameters, predictions of $\nu_{2}+3 \nu_{3}$ and $\nu_{1}+3 \nu_{3}$ bands have been carried out, as shown in Fig. 6 and Fig. 7, respectively, after anharmonic shift correction $\left(-0.274 \mathrm{~cm}^{-1}\right.$ for $\nu_{2}+3 \nu_{3}$ and $-0.581 \mathrm{~cm}^{-1}$ for $\left.\nu_{1}+3 \nu_{3}\right)$. We can see in these two predictions that the simulated spectra reproduce quite well the experimental spectra and thus may lead to assignments of the rovibrational lines.

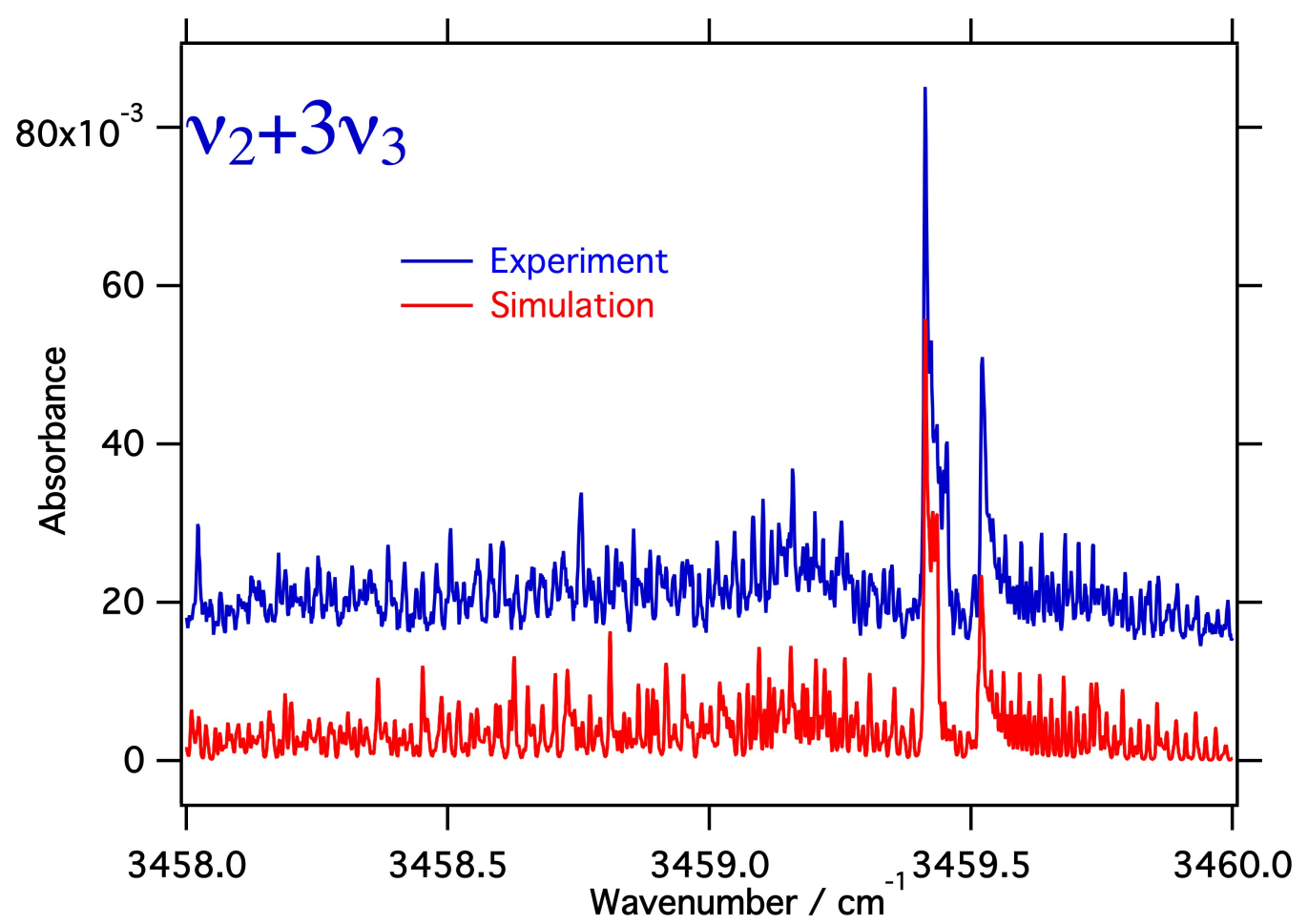

Figure 6. Comparison between an experimental spectrum (top curve, blue) (45 $\mathrm{m}$ optical path, $\left.4.6 \mathrm{mb} \mathrm{SF}_{6}, \mathrm{~T}=163 \mathrm{~K}\right)$ and a simulation (bottom, red curve) using the parameter of table 5 for $\nu_{2}+3 \nu_{3}$ band. The experiment curve has been shifted for clarity. 


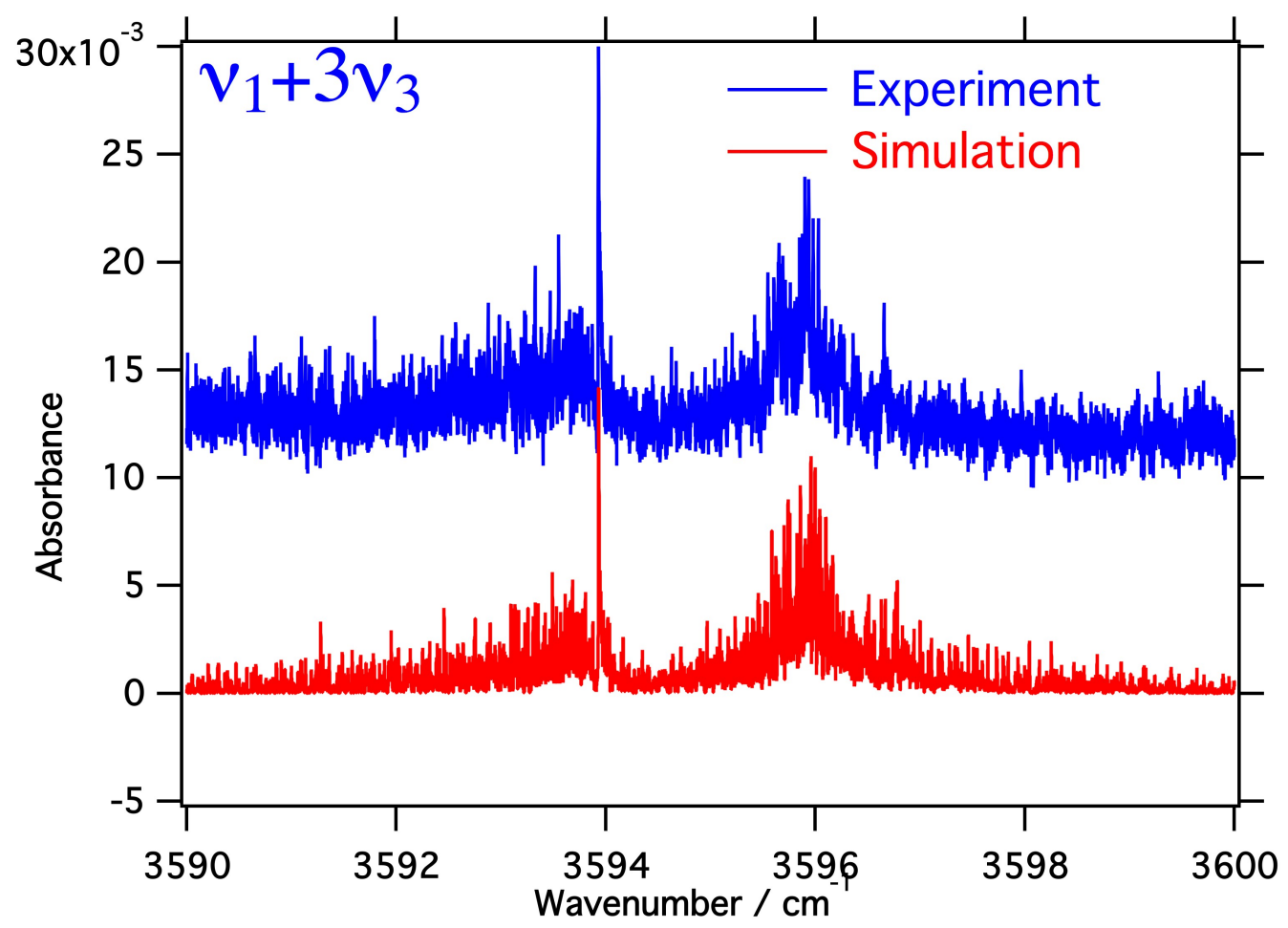

Figure 7. Comparison between an experimental spectrum (top curve, blue) (45 m optical path, $4.6 \mathrm{mb} \mathrm{SF}_{6}, \mathrm{~T}=163 \mathrm{~K}$ ) and a simulation (bottom, red curve) using the parameter in table 5 for $\nu_{1}+3 \nu_{3}$ band. The experiment curve has been shifted for clarity.

\section{Conclusion}

Combining various experimental parameters (optical path, pressure, spectral range) using HR FTIR, synchrotron radiation and a long path cryogenic cell, we have measured a number of vibrational bands involving the stretching modes of $\mathrm{SF}_{6}$ up to $\mathrm{v}_{1}, \mathrm{v}_{2}=1,2$ and $\mathrm{v}_{3}=1-3$. Using the tensorial formalism and the XTDS Dijon Software, a global fit of 11 rovibrationally resolved transitions has been carried out and a new optimized parameter set is proposed adding precision and global consistency for the interpretation of molecular spectroscopic parameters. It can also serve for the prediction of vibrational transitions up to four vibrational quanta, with description of the rotational structure. This model can serve as a basis for an extension to other multi quanta transitions of $\mathrm{SF}_{6}$ or other octahedral molecules of technological relevance.

\section{Acknowledgments}

We gratefully acknowledge the support from the DIM-Analytics program of the Ile de France Region and the LEFE-CHAT program of CNRS.

\section{References}

[1] C Schwab, A.J Damiao, C.A.B Silveira, J.W. Neri, M.G Destro, M.G Rodrigues, N.A.S Riva, Progress in Nuclear Energy 33 ( 1-2), 217 (1998).

[2] W Eerkens, B.J Kim, American Institute of Chemical Engineers (AiChE) Journal 56 (9), 2331 (2010).

[3] C.D Cantrell, A.A. Letokov, A.A. Makarov, Eds. Springer, Berlin , 3232 (1980)

[4] J.L Lyman, G.P. Quigley, O.P. Judd, Eds. Springer, Berlin, 3232 (1979)

[5] A.S. Pine, A.G. Robiette, J. Mol. Spectrosc. 80, 388 (1980). 
[6] C. Patterson, B.J. Krohn, A.S. Pine, J. Mol. Spectrosc. 88, 133 (1981).

[7] C. Patterson, F. Herlemont, M. Azizi, J. Lemaire, J. Mol. Spectrosc. 108, 31 (1984).

[8] C. Chapados, G. Birnbaum, J. Mol. Spectrosc. 132, 323 (1988).

[9] B. Bobin, C. Bord, J. Bord, C. Brant, J. Mol. Spectrosc. 121, 91 (1987).

[10] V. Boudon, and J.-P.Champion, T. Gabard, M. Loëte, F. Michelot, G. Pierre, M. Rotger, C. Wenger, M. Rey, J. Mol. Spectrosc. 251, 102 (2004), ISSN 0022-2852.

[11] O. Acef, C. Bordé, A. Clairon, G. Pierre, B. Sartakov, J. Mol. Spectrosc. 199, 188 (2000).

[12] V. Boudon, H. Bürger, E.B. M'Kami, J. Mol. Spectrosc. 205, 304 (2001).

[13] D. Bermejo, R.Z. Martinez, E. Loubignac, G. Pierre, J. Mol. Spectrosc. 201, 164 (2000).

[14] V. Boudon, D. Bermejo, J. Mol. Spectrosc. 213, 139 (2002).

[15] V. Boudon, J.L. Domenech, D Bermejo, H. Willner, J. Mol. Spectrosc. 228, 392 (2004).

[16] V. Boudon, L. Manceron, F. Kwabia Tchana, M. Loëte, L. Lago, P. Roy, Phys. Chem. Chem. Phys. 16, 1415 (2014).

[17] B. D. Hall, G. S. Dutton, D. J. Mondeel, J. D. Nance, M. Rigby, J. H. Butler, F. L. Moore, D. F. Hurst, J. W. Elkins, Atmos. Meas. Tech. 4, 2441-2451 (2011).

[18] V. Chin, L. Person, J. Mol. Spectrosc. 98, 258 (1983).

[19] W. Person, B. J. Krohn, J. Mol. Spectrosc. 98, 229 (1983).

[20] R. S. Mc Dowell, B. J. Krohn, H. Fliker, M. C. Vasquez, Spectrochim. Acta 42 A, 351 (1986).

[21] R. S. Mc Dowell, B. J. Krohn, Spectrochim. Acta 42 A, 371 (1986).

[22] H. Levene, D. S. Perry, J. Chem. Phys. 80(5), 1772 (1984).

[23] D. P. Hodgkinson, R. K. Heenan, A. R. Hoy, A. G. Robiette, Mol. Phys. 48, 193 (1984).

[24] D. P. Hodgkinson, J. C. Barrette, A. G. Robiette, Mol. Phys. 54, 927 (1985).

[25] K. T. Hetch, J. Mol. Spectrosc. 5, 355-389 (1960).

[26] J. Zhang, Q. Zhong, N. Wu, J. Wang, J. Zhao, Y. Xu, S. Guo, C. Ying, Phys. Lett. A 215, 291 (1996).

[27] P. Roy, J.B. Brubach, M. Rouzires, O. Pirali, L. Manceron, F. Kwabia Tchana, Rev. Electricité et Electronique 2, 23 (2008).

[28] J.B. Brubach, L. Manceron, M. Rouzires, O. Pirali, D. Balcon, F. Kwabia Tchana, V. Boudon, M. Tudorie, T. Huet, A. Cuisset, P. Roy, Infrared Physics and Technology, 112 (2009).

[29] F. K. Tchana, F. Willaert, X. Landsheere, J. - M. Flaud, L. Lago, M. Chapuis, P. Roy, L. Manceron, Rev. Sci. Inst. 84, 093101 (2013).

[30] M. Faye,, M. Bordessoule, B. Kanouté, P. Roy, L. Manceron, Rev. Sci. Inst. 870631192016.

[31] M. Faye, A. Leven, V. Boudon, L. Manceron, P. Asselin, F. Kwabia Tchana, P. Roy, Mol. Phys. 909059, 112 (2014).

[32] S. te Lintel. Hekkert, and A. F.Linskens, B. G Sartakov, G. Pierre, J. Reuss, J. Chem. Phys. 177, 181 (1993).

[33] M. Kelkhal, E. Rusinek, J. Legrand, F. Herlemont, and G.Pierre, J. Chem. Phys. 107(15), 5694 (1997).

[34] L.S. Rothman,, D. Jacquemart, A Barbe, D.C. Benner, M Birk, L.R. Brown, M.R. Carleer, C. Chackerian, K. Chance, L. Coudert, V. Dana, V. Malathy-Devi, J. M. Flaud, R. R. Gamache, A. Goldman, J.M. Hartmann, K.W. Jucks, A.G. Maki, J.Y. Mandin, S. Massie, J. Orphal, A. Perrin, C.P. Rinsland, M.A. Smith, R.A. Toth, J. Vander Auwera, P. Varanasi, G. Wagner, J. Quant. Spectrosc. Rad. Trans. 961392005.

[35] J. R. Ackerhalt, H. Fliker, H. W. Galbraith, J. King, and W. B. Person, J. Chem. Phys. 69, 1461 (1978).

[36] A. Robiette, D. Gray, F. Birss, Mol. Phys. 32 (6), 1591-1607 (1976).

\section{APPENDIX}

In this Appendix section we summarize in table 5, the effective Hamiltonian parameters resulting from the global fit presented above.

The ground state parameter values are fixed to 
Table 5. Effective Hamiltonian parameters. Standard deviation is given in parentheses, in the unit of the last two digits. Parameters for which no standard is given are fixed to literature value.

\begin{tabular}{|c|c|c|c|c|c|c|}
\hline Bande & Order & $\Omega(K, n \Gamma)$ & $\begin{array}{l}\text { Paramètres } \\
\{\mathrm{s}\}\end{array}$ & $\left\{\mathrm{s}^{\prime}\right\}$ & Values / $\mathrm{cm}^{-1}$ (St.Dev.) & $\begin{array}{l}\text { "Usual" notation, } \\
{[36] \text { and comments. }}\end{array}$ \\
\hline \multirow[t]{10}{*}{$\overline{\mathrm{GS}}$} & 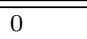 & $\overline{22\left(0,0 A_{1 g}\right)}$ & $\overline{0000000 A_{1 g}}$ & $\overline{0000000 A_{1 g}}$ & $99.1075666449 \times 10^{-2} \ddagger$ & $\overline{B_{0}}$ \\
\hline & 2 & $4\left(0,0 A_{1 g}\right)$ & $000000 A_{1 g}$ & $000000 A_{1 g}$ & $-7.2689461558 \times 10^{-9 \ddagger}$ & $-D_{0}$ \\
\hline & 2 & $4\left(4,0 A_{1 g}\right)$ & $000000 A_{1 g}$ & $000000 A_{1 g}$ & $1.2227986553 \times 10^{-10 \ddagger}$ & $-(\sqrt{15} / 4 \sqrt{2}) D_{0 t}$ \\
\hline & 4 & $6\left(0,0 A_{1 g}\right)$ & $000000 A_{1 g}$ & $000000 A_{1 g}$ & $2.3994500822 \times 10^{-13 \ddagger}$ & $H_{0}$ \\
\hline & 4 & $6\left(4,0 A_{1 g}\right)$ & $000000 A_{1 g}$ & $000000 A_{1 g}$ & $6.2051155575 \times 10^{-16 \ddagger}$ & $(3 \sqrt{5} / 16 \sqrt{2}) H_{4 t}$ \\
\hline & 4 & $6\left(6,0 A_{1 g}\right)$ & $000000 A_{1 g}$ & $000000 A_{1 g}$ & $1.7088642943 \times 10^{-15 \ddagger}$ & $-(\sqrt{231} / 64 \sqrt{2}) H_{4 t}$ \\
\hline & 6 & $8\left(0,0 A_{1 g}\right)$ & $000000 A_{1 g}$ & $000000 A_{1 g}$ & $-2.3273163437 \times 10^{-17 \ddagger}$ & \\
\hline & 6 & $8\left(4,0 A_{1 g}\right)$ & $000000 A_{1 g}$ & $000000 A_{1 g}$ & $1.6814688738 \times 10^{-19 \ddagger}$ & $-(3 \sqrt{15} / 64 \sqrt{2}) L_{4 t}$ \\
\hline & 6 & $8\left(6,0 A_{1 g}\right)$ & $000000 A_{1 g}$ & $000000 A_{1 g}$ & $2.4028125090 \times 10^{-19 \ddagger}$ & $(3 \sqrt{77} / 256 \sqrt{2}) L_{6 t}$ \\
\hline & 6 & $8\left(8,0 A_{1 g}\right)$ & $000000 A_{1 g}$ & $000000 A_{1 g}$ & $4.4485213255 \times 10^{-20 \ddagger}$ & $(1 / 32 \sqrt{33}) L_{8 t}$ \\
\hline \multirow[t]{13}{*}{$\nu_{2}$} & 0 & $0\left(0,0 A_{1 g}\right)$ & $010000 E_{g}$ & $010000 E_{g}$ & $643.373626(43)$ & $\nu_{2}$ \\
\hline & 2 & $2\left(0,0 A_{1 g}\right)$ & $010000 E_{g}^{g}$ & $010000 E_{g}^{g}$ & $1.9089(70) \times 10^{-5}$ & $B_{2}-B_{0}$ \\
\hline & 2 & $2\left(2,0 E_{g}\right)$ & $010000 E_{g}^{g}$ & $010000 E_{g}$ & $3.4144(45) \times 10^{-5}$ & $\sqrt{3} b_{2}+(24 \sqrt{3} / 7) C_{6}$ \\
\hline & 3 & $3\left(3,0 A_{2 g}\right)$ & $010000 E_{g}^{g}$ & $010000 E_{g}$ & $-1.350(51) \times 10^{-8}$ & $(1 / 2) d_{2}$ \\
\hline & 4 & $4\left(0,0 A_{1 g}\right)$ & $010000 E_{g}$ & $010000 E_{g}$ & $-5.49(34) \times 10^{-10}$ & $-\left(D_{2}-D_{0}\right)$ \\
\hline & 4 & $4\left(2,0 E_{g}\right)$ & $010000 E_{g}^{g}$ & $010000 E_{g}$ & $1.13(13) \times 10^{-10}$ & \\
\hline & 4 & $4\left(4,0 A_{1 g}\right)$ & $010000 E_{g}$ & $010000 E_{g}$ & $-1.62(33) \times 10^{-11}$ & \\
\hline & 4 & $4\left(4,0 E_{g}\right)$ & $010000 E_{g}$ & $010000 E_{g}$ & $2.42(71) \times 10^{-11}$ & \\
\hline & 5 & $5\left(3,0 A_{2 g}\right)$ & $010000 E_{g}$ & $010000 E_{g}$ & $1.75(59) \times 10^{-13}$ & \\
\hline & 6 & $6\left(0,0 A_{1 g}\right)$ & $010000 E_{g}$ & $010000 E_{g}$ & $1.64(48) \times 10^{-14}$ & \\
\hline & 6 & $6\left(2,0 E_{g}\right)$ & $010000 E_{g}$ & $010000 E_{g}$ & $-6.52(90) \times 10^{-15}$ & \\
\hline & 6 & $6\left(4,0 A_{1 g}\right)$ & $010000 E_{g}^{g}$ & $010000 E_{g}$ & $1.73(36) \times 10^{-15}$ & \\
\hline & 6 & $6\left(4,0 E_{g}\right)$ & $010000 E_{g}$ & $010000 E_{g}$ & $2.71(79) \times 10^{-15}$ & \\
\hline \multirow[t]{4}{*}{$\nu_{1}$} & 0 & $0\left(0,0 A_{1 g}\right)$ & $100000 A_{1 g}$ & $100000 A_{1 g}$ & $774.545540(66)$ & \\
\hline & 2 & $2\left(0,0 A_{1 g}\right)$ & $100000 A_{1 g}$ & $100000 A_{1 g}$ & $-1.10712(47)) \times 10^{-4}$ & $B_{1}-B_{0}$ \\
\hline & 4 & $4\left(0,0 A_{1 g}\right)$ & $100000 A_{1 g}$ & $100000 A_{1 g}$ & $3.00(68) \times 10^{-11}$ & $-\left(D_{1}-D_{0}\right)$ \\
\hline & 4 & $4\left(4,0 A_{1 g}\right)$ & $100000 A_{1 g}$ & $100000 A_{1 g}$ & $6.4(1.2) \times 10^{-12}$ & \\
\hline \multirow[t]{33}{*}{$\nu_{3}$} & 0 & $0\left(0,0 A_{1 g}\right)$ & $001000 F_{1 u}$ & $001000 F_{1 u}$ & $948.1025121(21)$ & $\nu_{3}$ \\
\hline & 1 & $1\left(1,0 F_{1 g}\right)$ & $001000 F_{1 u}$ & $001000 F_{1 u}$ & $2.6754759(88) \times 10^{-1}$ & $3 \sqrt{2}(B \zeta)_{3} \nu_{3}$ (Coriolis) \\
\hline & 2 & $2\left(0,0 A_{1 g}\right)$ & $001000 F_{1 u}$ & $001000 F_{1 u}$ & $-1.310341(89) \times 10^{-4}$ & $B_{3}-B_{0}$ \\
\hline & 2 & $2\left(2,0 E_{g}\right)$ & $001000 F_{1 u}$ & $001000 F_{1 u}$ & $-1.58495(16) \times 10^{-4}$ & $-(1 / 2) \alpha_{220}^{3}-6 \alpha_{224}^{3}$ \\
\hline & 2 & $2\left(2,0 F_{2 g}\right)$ & $001000 F_{1 u}$ & $001000 F_{1 u}$ & $4.3836(16) \times 10^{-5}$ & $-(3 / 4) \alpha_{220}^{3}+6 \alpha_{224}^{3}$ \\
\hline & 3 & $3\left(1,0 F_{1 g}\right)$ & $001000 F_{1 u}$ & $001000 F_{1 u}$ & $3.208(54) \times 10^{-8}$ & $-(3 \sqrt{3} / 4 \sqrt{2}) F_{110}^{3}$ \\
\hline & 3 & $3\left(3,0 F_{1 g}\right)$ & $001000 F_{1 u}$ & $001000 F_{1 u}$ & $-7.7(4.1) \times 10^{-10}$ & $(3 / \sqrt{5} / 2) F_{134}^{3}$ \\
\hline & 4 & $4\left(0,0 A_{1 g}\right)$ & $001000 F_{1 u}$ & $001000 F_{1 u}$ & $-7.67(65) \times 10^{-11}$ & $-\left(D_{3}-D_{0}\right)$ \\
\hline & 4 & $4\left(2,0 E_{g}\right)$ & $001000 F_{1 u}$ & $001000 F_{1 u}$ & $-2.40(43) \times 10^{-10}$ & \\
\hline & 4 & $4\left(2,0 F_{2 g}\right)$ & $001000 F_{1 u}$ & $001000 F_{1 u}$ & $2.77(44) \times 10^{-10}$ & \\
\hline & 4 & $4\left(4,0 A_{1 g}\right)$ & $001000 F_{1 u}$ & $001000 F_{1 u}$ & $2.0(2.1) \times 10^{-12}$ & \\
\hline & 4 & $4\left(4,0 E_{g}\right)$ & $001000 F_{1 u}$ & $001000 F_{1 u}$ & $3.61(67) \times 10^{-10}$ & \\
\hline & 4 & $4\left(4,0 F_{2 g}\right)$ & $001000 F_{1 u}$ & $001000 F_{1 u}$ & $2.64(51) \times 10^{-10}$ & \\
\hline & 5 & $5\left(1,0 F_{1 g}\right)$ & $001000 F_{1 u}$ & $001000 F_{1 u}$ & $-3.2(1.0) \times 10^{-13}$ & \\
\hline & 5 & $5\left(3,0 F_{1 g}\right)$ & $001000 F_{1 u}$ & $001000 F_{1 u}$ & $2.71(37) \times 10^{-12}$ & \\
\hline & 5 & $5\left(5,0 F_{1 g}\right)$ & $001000 F_{1 u}$ & $001000 F_{1 u}$ & $2.52(39) \times 10^{-12}$ & \\
\hline & 5 & $5\left(5,1 F_{1 g}\right)$ & $001000 F_{1 u}$ & $001000 F_{1 u}$ & $0.998(93) \times 10^{-12}$ & \\
\hline & 6 & $6\left(0,0 A_{1 g}\right)$ & $001000 F_{1 u}$ & $001000 F_{1 u}$ & $1.6(1.3) \times 10^{-15}$ & \\
\hline & 6 & $6\left(2,0 E_{g}\right)$ & $001000 F_{1 u}$ & $001000 F_{1 u}$ & $-3.4226181004 \times 10^{-15 \dagger}$ & \\
\hline & 6 & $6\left(2,0 F_{2 g}\right)$ & $001000 F_{1 u}$ & $001000 F_{1 u}$ & $1.13(69) \times 10^{-15}$ & \\
\hline & 6 & $6\left(4,0 A_{1 g}\right)$ & $001000 F_{1 u}$ & $001000 F_{1 u}$ & $1.06(18) \times 10^{-15}$ & \\
\hline & 6 & $6\left(4,0 E_{g}\right)$ & $001000 F_{1 u}$ & $001000 F_{1 u}$ & $6.74(83) \times 10^{-15}$ & \\
\hline & 6 & $6\left(4,0 F_{2 g}\right)$ & $001000 F_{1 u}$ & $001000 F_{1 u}$ & $-5.08(38) \times 10^{-14}$ & \\
\hline & 6 & $6\left(6,0 A_{1 g}\right)$ & $001000 F_{1 u}$ & $001000 F_{1 u}$ & $-5.23(64) \times 10^{-16}$ & \\
\hline & 6 & $6\left(6,0 E_{g}\right)$ & $001000 F_{1 u}$ & $001000 F_{1 u}$ & $-5.37(45) \times 10^{-15}$ & \\
\hline & 6 & $6\left(6,0 F_{2 g}\right)$ & $001000 F_{1 u}$ & $001000 F_{1 u}$ & $-6.77(48) \times 10^{-14}$ & \\
\hline & 6 & $6\left(6,1 F_{2 g}\right)$ & $001000 F_{1 u}$ & $001000 F_{1 u}$ & $-1.5644920019 \times 10^{-15 \dagger}$ & \\
\hline & 7 & $7\left(1,0 F_{1 g}\right)$ & $001000 F_{1 u}$ & $001000 F_{1 u}$ & $-2.39(56) \times 10^{-17}$ & \\
\hline & 7 & $7\left(3,0 F_{1 g}\right)$ & $001000 F_{1 u}$ & $001000 F_{1 u}$ & $3.4(1.0) \times 10^{-17}$ & \\
\hline & 7 & $7\left(5,0 F_{1 g}\right)$ & $001000 F_{1 u}$ & $001000 F_{1 u}$ & $2.04(74) \times 10^{-17}$ & \\
\hline & 7 & $7\left(5,1 F_{1 g}\right)$ & $001000 F_{1 u}$ & $001000 F_{1 u}$ & $3.29(62) \times 10^{-17}$ & \\
\hline & 7 & $7\left(7,0 F_{1 g}\right)$ & $001000 F_{1 u}$ & $001000 F_{1 u}$ & $1.6(1.8) \times 10^{-18}$ & \\
\hline & 7 & $7\left(7,1 F_{1 g}\right)$ & $001000 F_{1 u}$ & $001000 F_{1 u}$ & $6.6(5.0) \times 10^{-18}$ & \\
\hline \multirow{18}{*}{$\nu_{2}+\nu_{3}$} & 2 & $0\left(0,0 A_{1 g}\right)$ & $011000 F_{1 u}$ & $011000 F_{1 u}$ & $-3.759037(85)$ & $F_{1 u}$ Sublevel \\
\hline & 3 & $1\left(1,0 F_{1 g}\right)$ & $011000 F_{1 u}$ & $011000 F_{1 u}$ & $5.0043(58) \times 10^{-3}$ & $F_{1 u}$ Coriolis \\
\hline & 4 & $2\left(0,0 A_{1 g}\right)$ & $011000 F_{1 u}$ & $011000 F_{1 u}$ & $2.228(13) \times 10^{-5}$ & \\
\hline & 4 & $2\left(2,0 E_{g}\right)$ & $011000 F_{1 u}$ & $011000 F_{1 u}$ & $1.3648(89) \times 10^{-5}$ & \\
\hline & 4 & $2\left(2,0 F_{2 g}\right)$ & $011000 F_{1 u}$ & $011000 F_{1 u}$ & $-3.318(16) \times 10^{-5}$ & \\
\hline & 5 & $3\left(1,0 F_{1 g}\right)$ & $011000 F_{1 u}$ & $011000 F_{1 u}$ & $4.06(42) \times 10^{-8}$ & \\
\hline & 5 & $3\left(3,0 F_{1 g}\right)$ & $011000 F_{1 u}$ & $011000 F_{1 u}$ & $1.032(34) \times 10^{-7}$ & \\
\hline & 3 & $1\left(1,0 F_{1 g}\right)$ & $011000 F_{1 u}$ & $011000 F_{2 u}$ & $-3.9093138624 \times 10^{-4 \dagger}$ & $F_{1 u}-F_{1 u}$ Interaction \\
\hline & 4 & $2\left(2,0 E_{g}\right)$ & $011000 F_{1 u}$ & $011000 F_{2 u}$ & $-2.5563(85) \times 10^{10-5}$ & \\
\hline & 4 & $2\left(2,0 F_{2 g}\right)$ & $011000 F_{1 u}$ & $011000 F_{2 u}$ & $-3.52(25) \times 10^{-6}$ & \\
\hline & 5 & $3\left(1,0 F_{1 g}\right)$ & $011000 F_{1 u}$ & $011000 F_{2 u}$ & $-1.15(13) \times 10^{-8}$ & \\
\hline & 2 & $0\left(0,0 A_{1 g}\right)$ & $011000 F_{2 u}$ & $011000 F_{2 u}$ & $-2.8537(19) \times 10^{-1}$ & $F_{2 u}$ Sublevel \\
\hline & 3 & $1\left(1,0 F_{1 g}\right)$ & $011000 F_{2 u}$ & $011000 F_{2 u}$ & $2.761(12) \times 10^{-3}$ & $F_{2 u}$ Coriolis \\
\hline & 4 & $2\left(0,0 A_{1 g}\right)$ & $011000 F_{2 u}$ & $011000 F_{2 u}$ & $-3.203(20) \times 10^{-5}$ & \\
\hline & 4 & $2\left(2,0 E_{g}\right)$ & $011000 F_{2 u}$ & $011000 F_{2 u}$ & $-2.498(17) \times 10^{-5}$ & \\
\hline & 4 & $2\left(2,0 F_{2 g}\right)$ & $011000 F_{2 u}$ & $011000 F_{2 u}$ & $2.380(21) \times 10^{-5}$ & \\
\hline & 5 & $3\left(1,0 F_{1 g}\right)$ & $011000 F_{2 u}$ & $011000 F_{2 u}$ & $-9.41(46) \times 10^{-8}$ & \\
\hline & 5 & $3\left(3,0 F_{1 g}\right)$ & $011000 F_{2 u}$ & $011000 F_{2 u}$ & $-5.85(44) \times 10^{-8}$ & \\
\hline
\end{tabular}




\begin{tabular}{|c|c|c|c|c|c|c|}
\hline Bande & Order & $\Omega(K, n \Gamma)$ & $\begin{array}{l}\text { Paramètres } \\
\{\mathrm{s}\}\end{array}$ & $\left\{\mathrm{s}^{\prime}\right\}$ & Values $/ \mathrm{cm}^{-1}$ (St.Dev.) & "Usual" notation \\
\hline \multirow[t]{4}{*}{$2 \nu_{1}$} & 2 & $0\left(0,0 A_{1 g}\right)$ & $200000 A_{1 g}$ & $200000 A_{1 g}$ & -1.7346356396 & Anharmonicit $2 X_{11}$ \\
\hline & 4 & $2\left(0,0 A_{1 g}\right)$ & $200000 A_{1 g}$ & $200000 A_{1 g}$ & $-1.2576597821 \times 10^{-5}$ & $\Delta B_{11}$ \\
\hline & 6 & $4\left(0,0 A_{1 g}\right)$ & $200000 A_{1 g}$ & $200000 A_{1 g}$ & $-4.9546135312 \times 10^{-9}$ & $-\Delta D_{11}$ \\
\hline & 6 & $4\left(4,0 A_{1 g}\right)$ & $200000 A_{1 g}$ & $200000 A_{1 g}$ & $-7.7163949322 \times 10^{-11}$ & $-(\sqrt{15} / 4 \sqrt{2}) D_{11 t}$ \\
\hline \multirow[t]{4}{*}{$\nu_{1}+\nu_{3}$} & 2 & $0\left(0,0 A_{1 g}\right)$ & $101000 F_{1 u}$ & $101000 F_{1 u}$ & $-2.908879(81)$ & Anharmonicit $X_{13}$ \\
\hline & 3 & $1\left(1,0 F_{1 g}\right)$ & $101000 F_{1 u}$ & $101000 F_{1 u}$ & $-7.91(22) \times 10^{-5}$ & Coriolis \\
\hline & 4 & $2\left(0,0 A_{1 g}\right)$ & $101000 F_{1 u}$ & $101000 F_{1 u}$ & $-7.1(4.8) \times 10^{-8}$ & \\
\hline & 4 & $2\left(2,0 E_{g}\right)$ & $101000 F_{1 u}$ & $101000 F_{1 u}$ & $2.976(71) \times 10^{-6}$ & \\
\hline \multirow[t]{21}{*}{$\nu_{1}+\nu_{2}+\nu_{3}$} & 4 & $0\left(0,0 A_{1 g}\right)$ & $111000 F_{1 u}$ & $111000 F_{1 u}$ & $-2.39186(13)$ & $F_{1 u}$ Sublevel \\
\hline & 5 & $1\left(1,0 F_{1 g}\right)$ & $111000 F_{1 u}$ & $111000 F_{1 u}$ & $8.42(20) \times 10^{-4}$ & \\
\hline & 6 & $2\left(0,0 A_{1 g}\right)$ & $111000 F_{1 u}$ & $111000 F_{1 u}$ & $3.100(96) \times 10^{-4}$ & \\
\hline & 6 & $2\left(2,0 E_{g}\right)$ & $111000 F_{1 u}$ & $111000 F_{1 u}$ & $2.351(72) \times 10^{-4}$ & \\
\hline & 6 & $2\left(2,0 F_{2 g}\right)$ & $111000 F_{1 u}$ & $111000 F_{1 u}$ & $-3.46(11) \times 10^{-4}$ & \\
\hline & 7 & $3\left(1,0 F_{1 g}\right)$ & $111000 F_{1 u}$ & $111000 F_{1 u}$ & $-1.52(15) \times 10^{-7}$ & \\
\hline & 7 & $3\left(3,0 F_{1 g}\right)$ & $111000 F_{1 u}$ & $111000 F_{1 u}$ & $1.60(18) \times 10^{-7}$ & \\
\hline & 5 & $1\left(1,0 F_{1 g}\right)$ & $111000 F_{1 u}$ & $111000 F_{2 u}$ & $-1.500(45) \times 10^{-2}$ & $F_{1 u}-F_{1 u}$ interaction \\
\hline & 6 & $2\left(2,0 E_{g}\right)$ & $111000 F_{1 u}$ & $111000 F_{2 u}$ & $-2.221(67) \times 10^{-4}$ & \\
\hline & 6 & $2\left(2,0 F_{2 g}\right)$ & $111000 F_{1 u}$ & $111000 F_{2 u}$ & $-7.39(42) \times 10^{-6}$ & \\
\hline & 7 & $3\left(1,0 F_{1 g}\right)$ & $111000 F_{1 u}$ & $111000 F_{2 u}$ & $-1.048(58) \times 10^{-6}$ & \\
\hline & 7 & $3\left(3,0 A_{2 g}\right)$ & $111000 F_{1 u}$ & $111000 F_{2 u}$ & $-1.93(11) \times 10^{-7}$ & \\
\hline & 7 & $3\left(3,0 F_{1 g}\right)$ & $111000 F_{1 u}$ & $111000 F_{2 u}$ & $7.04(24) \times 10^{-8}$ & \\
\hline & 7 & $3\left(3,0 F_{2 g}\right)$ & $111000 F_{1 u}$ & $111000 F_{2 u}$ & $-3.42(12) \times 10^{-7}$ & \\
\hline & 4 & $0\left(0,0 A_{1 g}\right)$ & $111000 F_{2 u}$ & $111000 F_{2 u}$ & $-2.48157(26)$ & $F_{2 u}$ Sublevel \\
\hline & 5 & $1\left(1,0 F_{1 g}\right)$ & $111000 F_{2 u}$ & $111000 F_{2 u}$ & $-2.855(24) \times 10^{-3}$ & \\
\hline & 6 & $2\left(0,0 A_{1 g}\right)$ & $111000 F_{2 u}$ & $111000 F_{2 u}$ & $-2.982(95) \times 10^{-4}$ & \\
\hline & 6 & $2\left(2,0 E_{g}\right)$ & $111000 F_{2 u}$ & $111000 F_{2 u}$ & $-2.143(72) \times 10^{-4}$ & \\
\hline & 6 & $2\left(2,0 F_{2 g}\right)$ & $111000 F_{2 u}$ & $111000 F_{2 u}$ & $3.41(11) \times 10^{-4}$ & \\
\hline & 7 & $3\left(1,0 F_{1 g}\right)$ & $111000 F_{2 u}$ & $111000 F_{2 u}$ & $-1.00(14) \times 10^{-7}$ & \\
\hline & 7 & $3\left(3,0 F_{1 g}\right)$ & $111000 F_{2 u}$ & $111000 F_{2 u}$ & $2.28(18) \times 10^{-7}$ & \\
\hline \multirow[t]{40}{*}{$2 \nu_{3}$} & 2 & $0\left(0,0 A_{1 g}\right)$ & $002000 A_{1 g}$ & $002000 A_{1 g}$ & $-7.195264(72)$ & $A_{1 g}=2 X_{33}-2 G_{33}$ \\
\hline & 4 & $2\left(0,0 A_{1 g}\right)$ & $002000 A_{1 g}$ & $002000 A_{1 g}$ & $2.003(72) \times 10^{-6}$ & \\
\hline & 6 & $4\left(0,0 A_{1 g}\right)$ & $002000 A_{1 g}$ & $002000 A_{1 g}$ & $1.95(17) \times 10^{-10}$ & \\
\hline & 6 & $4\left(4,0 A_{1 g}\right)$ & $002000 A_{1 g}$ & $002000 A_{1 g}$ & $5.70(25) \times 10^{-11}$ & \\
\hline & 4 & $2\left(2,0 E_{g}\right)$ & $002000 A_{1 g}$ & $002000 E_{g}$ & $-7.99(57) \times 10^{-7}$ & \\
\hline & 6 & $4\left(2,0 E_{g}\right)$ & $002000 A_{1 g}$ & $002000 E_{g}$ & $-7.13(95) \times 10^{-11}$ & \\
\hline & 6 & $4\left(4,0 E_{g}\right)$ & $002000 A_{1 g}$ & $002000 E_{g}$ & $1.43(14) \times 10^{-10}$ & \\
\hline & 4 & $2\left(2,0 F_{2 g}\right)$ & $002000 A_{1 g}$ & $002000 F_{2 g}$ & $-2.72(26) \times 10^{-6}$ & \\
\hline & 5 & $3\left(3,0 F_{2 g}\right)$ & $002000 A_{1 g}$ & $002000 F_{2 g}$ & $-4.04(79) \times 10^{-8}$ & \\
\hline & 6 & $4\left(2,0 F_{2 g}\right)$ & $002000 A_{1 g}$ & $002000 F_{2 g}$ & $-1.90(25) \times 10^{-10}$ & \\
\hline & 6 & $4\left(4,0 F_{2 g}\right)$ & $002000 A_{1 g}$ & $002000 F_{2 g}$ & $-9.8(1.6) \times 10^{-11}$ & \\
\hline & 2 & $0\left(0,0 A_{1 g}\right)$ & $002000 E_{g}$ & $002000 E_{g}$ & $-4.630220(24)$ & $E_{g}=2 X_{33}+6 G_{33}+12 T_{33}$ \\
\hline & 4 & $2\left(0,0 A_{1 g}\right)$ & $002000 E_{g}$ & $002000 E_{g}$ & $-1.379(11) \times 10^{-4}$ & \\
\hline & 4 & $2\left(2,0 E_{g}\right)$ & $002000 E_{g}$ & $002000 E_{g}$ & $-1.1931(98) \times 10^{-4}$ & \\
\hline & 5 & $3\left(3,0 A_{2 g}\right)$ & $002000 E_{g}^{g}$ & $002000 E_{g}^{g}$ & $6.0(1.9) \times 10^{-9}$ & \\
\hline & 6 & $4\left(0,0 A_{1 g}\right)$ & $002000 E_{g}$ & $002000 E_{g}$ & $3.528(70) \times 10^{-9}$ & \\
\hline & 6 & $4\left(2,0 E_{g}\right)$ & $002000 E_{g}$ & $002000 E_{g}$ & $-1.681(28) \times 10^{-9}$ & \\
\hline & 6 & $4\left(4,0 A_{1 g}\right)$ & $002000 E_{g}$ & $002000 E_{g}$ & $3.4708425825 \times 10^{-11}$ & \\
\hline & 6 & $4\left(4,0 E_{g}\right)$ & $002000 E_{g}$ & $002000 E_{g}$ & $2.98(25) \times 10^{-10}$ & \\
\hline & 3 & $1\left(1,0 F_{1 g}\right)$ & $002000 E_{g}$ & $002000 F_{2 g}$ & $-4.884(34) \times 10^{-3}$ & \\
\hline & 4 & $2\left(2,0 F_{2 g}\right)$ & $002000 E_{g}$ & $002000 F_{2 g}$ & $6.319(54) \times 10^{-5}$ & \\
\hline & 5 & $3\left(1,0 F_{1 g}\right)$ & $002000 E_{g}$ & $002000 F_{2 g}$ & $3.69(13) \times 10^{-8}$ & \\
\hline & 5 & $3\left(3,0 F_{1 g}\right)$ & $002000 E_{g}$ & $002000 F_{2 g}$ & $-4.01(13) \times 10^{-8}$ & \\
\hline & 5 & $3\left(3,0 F_{2 g}\right)$ & $002000 E_{g}$ & $002000 F_{2 g}$ & $2.34(36) \times 10^{-8}$ & \\
\hline & 6 & $4\left(2,0 F_{2 g}\right)$ & $002000 E_{g}$ & $002000 F_{2 g}$ & $1.438(30) \times 10^{-9}$ & \\
\hline & 6 & $4\left(4,0 F_{1 g}\right)$ & $002000 E_{g}^{g}$ & $002000 F_{2 g}$ & $2.87(49) \times 10^{-10}$ & \\
\hline & 6 & $4\left(4,0 F_{2 g}\right)$ & $002000 E_{g}$ & $002000 F_{2 g}$ & $9.42(29) \times 10^{-10}$ & \\
\hline & 2 & $0\left(0,0 A_{1 g}\right)$ & $002000 F_{2 g}$ & $002000 F_{2 g}$ & $3.489013(37) \times 10^{-1}$ & $F_{2 g}=2 X_{33}+4 G_{33}-8 T_{33}$ \\
\hline & 3 & $1\left(1,0 F_{1 g}\right)$ & $002000 F_{2 g}$ & $002000 F_{2 g}$ & $5.460(20) \times 10^{-4}$ & \\
\hline & 4 & $2\left(0,0 A_{1 g}\right)$ & $002000 F_{2 g}$ & $002000 F_{2 g}$ & $8.895(77) \times 10^{-5}$ & \\
\hline & 4 & $2\left(2,0 E_{g}\right)$ & $002000 F_{2 g}$ & $002000 F_{2 g}$ & $-1.352(12) \times 10^{-4}$ & \\
\hline & 4 & $2\left(2,0 F_{2 g}\right)$ & $002000 F_{2 g}$ & $002000 F_{2 g}$ & $1.0343(87) \times 10^{-4}$ & \\
\hline & 5 & $3\left(1,0 F_{1 g}\right)$ & $002000 F_{2 g}$ & $002000 F_{2 g}$ & $-2.40(29) \times 10^{-8}$ & \\
\hline & 5 & $3\left(3,0 F_{1 g}\right)$ & $002000 F_{2 g}$ & $002000 F_{2 g}$ & $-2.07(26) \times 10^{-8}$ & \\
\hline & 6 & $4\left(0,0 A_{1 g}\right)$ & $002000 F_{2 g}$ & $002000 F_{2 g}$ & $-3.056(55) \times 10^{-9}$ & \\
\hline & 6 & $4\left(2,0 E_{g}\right)$ & $002000 F_{2 g}$ & $002000 F_{2 g}$ & $-2.728(42) \times 10^{-9}$ & \\
\hline & 6 & $4\left(2,0 F_{2 g}\right)$ & $002000 F_{2 g}$ & $002000 F_{2 g}$ & $2.535(46) \times 10^{-9}$ & \\
\hline & 6 & $4\left(4,0 A_{1 g}\right)$ & $002000 F_{2 g}$ & $002000 F_{2 g}$ & $-1.074(44) \times 10^{-10}$ & \\
\hline & 6 & $4\left(4,0 E_{g}\right)$ & $002000 F_{2 g}$ & $002000 F_{2 g}$ & $7.93(30) \times 10^{-10}$ & \\
\hline & 6 & $4\left(4,0 F_{2 g}\right)$ & $002000 F_{2 g}$ & $002000 F_{2 g}$ & $1.346(46) \times 10^{-9}$ & \\
\hline
\end{tabular}




\begin{tabular}{|c|c|c|c|c|c|c|}
\hline Bande & Order & $\Omega(K, n \Gamma)$ & $\begin{array}{l}\text { Paramètres } \\
\{\mathrm{s}\}\end{array}$ & $\left\{\mathrm{s}^{\prime}\right\}$ & Values / $\mathrm{cm}^{-1}$ (St.Dev) & "Usual" notation \\
\hline \multirow[t]{14}{*}{$3 \nu_{3}$} & 4 & $0\left(0,0 A_{1 g}\right)$ & $003000 F_{1 u}$ & $003000 F_{1 u}$ & $-1.981(22) \times 10^{-1}$ & Sous niveau $F_{1}^{\left(l_{3}\right)=1}$ \\
\hline & 5 & $1\left(1,0 F_{1 g}\right)$ & $003000 F_{1 u}$ & $003000 F_{1 u}$ & $-9.102(88) \times 10^{-3}$ & $F_{1 u}$ Coriolis \\
\hline & 6 & $2\left(0,0 A_{1 g}\right)$ & $003000 F_{1 u}$ & $003000 F_{1 u}$ & $-4.07(18) \times 10^{-6}$ & \\
\hline & 4 & $0\left(0,0 A_{1 g}\right)$ & $003000 F_{1 u}$ & $003000 F_{1 u}$ & $-2.218(16) \times 10^{-1}$ & Interaction $F_{1 u}^{\left(l_{3}\right)=1}-F_{1 u}^{\left(l_{3}\right)=3}$ \\
\hline & 5 & $1\left(1,0 F_{1 g}\right)$ & $003000 F_{1 u}$ & $003000 F_{1 u}$ & $6.481(56) \times 10^{-3}$ & \\
\hline & 6 & $2\left(0,0 A_{1 g}\right)$ & $003000 F_{1 u}$ & $003000 F_{1 u}$ & $-8.1(2.8) \times 10^{-7}$ & \\
\hline & 4 & $0\left(0,0 A_{1 g}\right)$ & $003000 A_{2 u}$ & $003000 A_{2 u}$ & $-3.01(11) \times 10^{-2}$ & Sous niveau $A_{2 u}$ \\
\hline & 6 & $2\left(0,0 A_{1 g}\right)$ & $003000 A_{2 u}$ & $003000 A_{2 u}$ & $-9.2(7.4) \times 10^{-7}$ & \\
\hline & 4 & $0\left(0,0 A_{1 g}\right)$ & $003000 F_{1 u}$ & $003000 F_{1 u}$ & $2.633(22) \times 10^{-1}$ & Sous niveau $F_{1 u}^{\left(l_{3}\right)=3}$ \\
\hline & 5 & $1\left(1,0 F_{1 g}\right)$ & $003000 F_{1 u}$ & $003000 F_{1 u}$ & $3.413(36) \times 10^{-3}$ & \\
\hline & 6 & $2\left(0,0 A_{1 g}\right)$ & $003000 F_{1 u}$ & $003000 F_{1 u}$ & $5.41(25) \times 10^{-6}$ & \\
\hline & 4 & $0\left(0,0 A_{1 g}\right)$ & $003000 F_{2 u}$ & $003000 F_{2 u}$ & $-2.634(63) \times 10^{-2}$ & Sous niveau $F_{2 u}$ \\
\hline & 5 & $1\left(1,0 F_{1 g}\right)$ & $003000 F_{2 u}$ & $003000 F_{2 u}$ & $5.882(61) \times 10^{-3}$ & \\
\hline & 6 & $2\left(0,0 A_{1 g}\right)$ & $003000 F_{2 u}$ & $003000 F_{2 u}$ & $-3.42(35) \times 10^{-6}$ & \\
\hline
\end{tabular}

$\ddagger$ GS parameters are assumed enough good to be fixed in the fit.

$\dagger$ Parameters fixed to their initial values taken from a preliminary fit including less data. 